\title{
Revisão do gênero Opselater Costa (Coleoptera, Elateridae, Agrypninae)
}

\author{
Simone Policena Rosa ${ }^{1}$
}

\begin{abstract}
${ }^{1}$ Museu de Zoologia, Universidade de São Paulo. Caixa Postal 42494, 04218-970 São Paulo-SP, Brasil. Endereço eletrônico: simonepr@usp.br.
\end{abstract}

\begin{abstract}
Revision of the genus Opselater Costa (Coleoptera, Elateridae, Agrypninae). The genus Opselater Costa, 1975 is composed by bioluminescent elaterids, with small and lateral luminous spots on the base of pronotum, and slender body with elytra tapering to apices. They are distributed from Panama to Argentina. Seven species are redescribed, Opselater hebes (Germar, 1841), O. helvolus (Germar, 1841), O. lucens (Illiger, 1807), O. melanurus (Candèze, 1863), O. pyrophanus (Illiger, 1807), O. quadraticollis (Blanchard, 1843), and O. succinus Costa, 1980. O. costae sp. nov. is described, from Linhares - Espírito Santo, Brazil. A key to species and illustrations of most characters are also provided, including prothorax, pterothorax, wings and metendosternitum.
\end{abstract}

KEYwords. Agrypninae; Coleoptera; Elateridae; Opselater; taxonomy.

\begin{abstract}
Resumo. O gênero Opselater é formado por elaterídeos bioluminescentes, com vesículas luminescentes laterais, pequenas, localizadas na região posterior do pronoto, e corpo delgado com élitros gradualmente afilados do úmero ao ápice. Distribuem-se do Panamá à Argentina. São redescritas sete espécies, Opselater hebes (Germar, 1841), O. helvolus (Germar, 1841), O. lucens (Illiger, 1807), O. melanurus (Candèze, 1863), O. pyrophanus (Illiger, 1807), O. quadraticollis (Blanchard, 1843) e O. succinus Costa, 1980. O. costae sp. nov. de Linhares, Espírito Santo, é descrita. Também são apresentados uma chave para a identificação das espécies e ilustrações dos principais caracteres, incluindo protórax, pterotórax, asas e metendosternito.
\end{abstract}

Palavras-chave. Agrypninae; Coleoptera; Elateridae; Opselater; taxonomia.

O gênero Opselater pertence à subtribo Pyrophorina Costa, 1975, juntamente com outros 10 gêneros de elaterídeos bioluminescentes, caracterizados pela fronte carenada e esclerito ventral do pênis livre. O gênero foi erigido por CosTA (1975) para agrupar seis espécies anteriormente incluídas no gênero Pyrophorus Billberg, 1820. Em 1980, Costa revisou essas seis espécies e descreveu uma nova. No presente trabalho, Opselater e suas espécies são redescritos e uma nova espécie é descrita, totalizando oito espécies para o gênero, com distribuição da América Central à Argentina. São vaga-lumes de tamanho médio $(15,6-32 \mathrm{~mm})$, com élitros gradualmente afilados e com vesículas luminescentes laterais sobre a base do pronoto, pequenas ou quase indistintas. Distinguem-se dos demais gêneros de Pyrophorini pela forma do esclerito dorsal do pênis, geralmente com abaulamentos laterais menores, recobertos por minúsculas escamas, e com esclerito ventral liso.

Este trabalho representa uma contribuição ao reconhecimento dos elaterídeos bioluminescentes, onde são tratados caracteres morfológicos usualmente empregados para o grupo e caracteres novos, como a forma e o comprimento relativo dos antenômeros, a forma do órgão abdominal, a presença de strigae nos élitros e a carena látero-apical dos parâmeros. Asas, peças bucais, protórax , pterotórax e metendosternito são ilustrados pela primeira vez para o gênero e poderão servir de base para estudos da tribo como um todo. Também são apresentados uma chave atualizada para a identificação das espécies e alguns dados de biologia como subsídios para futuros estudos sobre o comportamento desses insetos.

\section{MATERIAL E MÉTODOS}

O material estudado pertence às seguintes instituições: American Museum of Natural History, New York (AMNH); Departamento de Zoologia da Universidade Federal do Paraná, Curitiba (DZUP); Deutsches Entomologisches Institut, Eberswalde (DEIC); Field Museum of Natural History, Chicago (FMNH); Forschungsinstitut und Natur-Museum Seckenberg, Frankfurt (SMFD); Institut Royal des Sciences Naturelles de Belgique, Bruxelles (ISNB); Instituto Biológico, São Paulo (IBSP); Museu Anchieta, Porto Alegre (MAPA); Museu de Ciências Naturais, Fundação Zoobotânica do Rio Grande do Sul, Porto Alegre (MCNZ); Museu Nacional ( ex Coleção Campos Seabra), Universidade Federal do Rio de Janeiro, Rio de Janeiro (MNRJ); Museu de Zoologia da Universidade de São Paulo, São Paulo (MZSP); Museum für Naturkunde der Humboldt Universität zu Berlin, Berlin (ZMHB); Muséum National d'Histoire Naturelle, Paris (MNHN); Museum of Comparative Zoology, Cambridge (MCZC); Zoologiska Museet, Naturhistoriska Centralmuseet, Helsingfors (MZHF); Naturhistoriska Riksmuseet, Stockholm (NHRS); The Natural History Museum, London (BMNH); United States National Museum, Washington (USNM); Zoologisk Museum, Københavns Universitet, Københavns (ZMUC).

A metodologia empregada para as dissecções, ilustrações e mensurações foi segundo CALDER (1996) e CASARI-CHEN (1993). As informações sobre as localidades dos espécimens foram obtidas nos rótulos do material examinado e na literatura pertinente. Para o levantamento dessas localidades foram consultados Hanson (1945), Bokermann (1966), Vanzolini \& 
Papavero (1968) e Stephens \& Traylor (1983).

Para a descrição de todos os caracteres, exceto genitálias e asas, a terminologia utilizada segue Costa $(1975,1978,1980)$, CAlder $(1981,1996)$ e CAlder et al. (1993). Para as veias das asas foi adotada a terminologia proposta por KUKALOVÁ-PECK \& LAWRENCE (1993) e para as genitálias masculina e feminina, LAWRENCE \& Britton (1994) e CALder (1996). A terminologia utilizada para o trato genital feminino baseia-se nos trabalhos de Williams (1945), Becker (1956) e CAlder (1996).

\section{Opselater Costa, 1975}

Opselater Costa, 1975: 103 (desc.); 1980: 164 (rev.); Golbach, 1994: 29 (chave).

Espécie-tipo: Elater pyrophanus Illiger, 1807 (designação original).

Diagnose. Besouros de tamanho médio (15,6-32 mm). Tegumento castanho-claro a castanho-escuro, ou castanhoalaranjado a castanho-avermelhado, revestido por pilosidade densa, curta, amarelada ou acinzentada. Antenas serreadas a partir do quarto antenômero; comprimento dos $2^{\circ}$ e $3^{\circ}$ antenômeros juntos subigual ao do quarto. Vesículas luminescentes da base do pronoto pequenas, laterais. Élitros gradualmente afilados do úmero até os ápices. Edeago com pênis formado por um esclerito dorsal, geralmente com margens laterais, próximas aos prolongamentos basais, com um abaulamento em cada lado, recobertos ou não por minúsculas escamas; e um esclerito ventral liso, de formato variável.

Redescrição. Macho. Fronte quadrangular, levemente declinada, proeminente, com margem anterior carenada, superfície quase plana ou côncava; pontuação variável. Antenas com 11 antenômeros, serreadas a partir do $4^{\circ}$ antenômero, ultrapassando, ou não, o ângulo posterior do pronoto; $3^{\circ}$ antenômero mais longo ou subigual ao $2^{\circ}$, os dois juntos do mesmo comprimento do $4^{\circ}$. Olhos bem desenvolvidos, finamente facetados. Labrum muito esclerotizado, de forma semicircular, fortemente pontuado e piloso. Mandíbulas (Fig. 4) simétricas, curtas e largas, ápices gradualmente curvos, com pequeno dente subapical e penicilo bem desenvolvido; região dorso-lateral grosseiramente pontuada, com cerdas longas. Maxilas (Fig. 3) com gálea e lacínia membranosas, em forma de lobo, densamente pilosas; cardo e medistipe com cerdas curtas e finas; basistipe com cerdas longas e fortes; palpos maxilares 4-articulados, último artículo securiforme. Lábio (Fig. 2) com premento membranoso, com cerdas curtas; mento com cerdas longas; palpos com três artículos, último artículo securiforme.

Protórax (Figs. 6, 7) com carenas laterais completas. Pronoto convexo, geralmente com pequeno tubérculo basal agudo; pontuação heterogênea. Vesículas luminescentes pequenas e achatadas, laterais, próximas à base, não atingindo a margem posterior. Ângulos anteriores curtos e arredondados. Ângulos posteriores proeminentes, unicarenados. Prosterno com pontuação heterogênea. Comprimento do processo prosternal 2,5 vezes a largura da procoxa. Hipômeros com pontuação densa e umbilicada, espaços entre os pontos micropontuados; pilosidade fina e curta.

Mesoventrito (fig. 8) com terço posterior elevado $45^{\circ}$ acima do nível da região anterior. Cavidade mesoventral profunda, de lados subparalelos, gradualmente convergentes próximo às mesocoxas, 2,1 vezes mais longa que larga. Mesocoxas (Fig. 5) fechadas pelo mesepimero e mesepisterno, largamente separadas; mesotrocantin exposto. Cavidade mesocoxal levemente transversal, oblíqua. Escutelo (Fig. 10) pentagonal com declividade posterior, abruptamente elevado acima do mesoscuto. Sutura meso-metaventral presente.

Metaventrito (Fig. 5) com pontuação fina, espaçada na região mediana e moderadamente densa nas laterais. Metacoxas horizontais, contíguas, estendendo-se lateralmente até os élitros. Placas metacoxais bem desenvolvidas, estreitando-se gradualmente em direção às margens laterais. Sutura longitudinal mediana com comprimento 0,6 vezes o comprimento do metaventrito. Metepisterno, aproximadamente, 6,7 vezes mais longo que largo. Metendosternito (Fig. 9) com processo anterior longo, tendões anteriores contíguos na base; braços laterais curtos; processos látero-ventrais presentes, pouco desenvolvidos; lâminas ausentes.

Ventritos com pontuação fina e espaçada na região mediana; média e densa nas margens laterais (ventritos I-V) e posterior (ventrito V). Órgão luminescente (Figs. 11, 12) pequeno (ocupando $1 / 5$ ou $1 / 4$ da largura do primeiro esternito).

Élitros com strigae forte ou fracamente marcadas; interestrias achatadas com pontuação fina e moderadamente densa; lados gradualmente afilados do úmero ao ápice; ápices afilados ou mucronados, deiscentes.

Asas (Fig. 1) com célula radial bem desenvolvida, alongada, com ângulo interno posterior basal reto; $\mathrm{CuA}_{1}$ presente, localizada entre $\mathrm{MP}_{3+4}$ e $\mathrm{CuA}_{2}$, como uma veia transversal; área medial com 5 veias livres; área apical com duas esclerotizações e comprimento aproximadamente igual a 1/7 do comprimento total da asa.

Pernas delgadas e pilosas. Tíbias comprimidas lateralmente, com dois esporões apicais, látero-ventrais; margens interna e externa e ápice com uma série de cerdas espiniformes. Tarsômeros simples, vertical ou obliquamente truncados na extremidade distal, face ventral densamente pilosa, tarsômeros 1 e 2 com cerdas espiniformes apicais nas margens externa e interna. Garras tarsais simples, com duas cerdas na superfície da base ventral externa e várias cerdas na superfície dorsal.

Genitália masculina. Tergito VIII. (Fig. 38) uniformemente esclerotizado, subtriangular, com base quase reta e ápice arredondado; margens látero-distais e posterior com cerdas longas. Esternito VIII. (Fig. 37) transverso, parcialmente membranoso, de lados subparalelos, com base proeminente e sinuosa, ápice emarginado; margens látero-distais com cerdas longas. Esternito IX e tergito IX (Figs. 35, 36) fusionados basalmente. Esternito IX alongado, parcialmente membranoso, com base quase reta e ápice arredondado; região esclerotizada com cerdas longas. Tergito IX com base quase reta e ápice bilobado; margens látero-distais com cerdas curtas e longas. Tergito X (Fig. 36) membranoso, arredondado. Edeago. Peça 

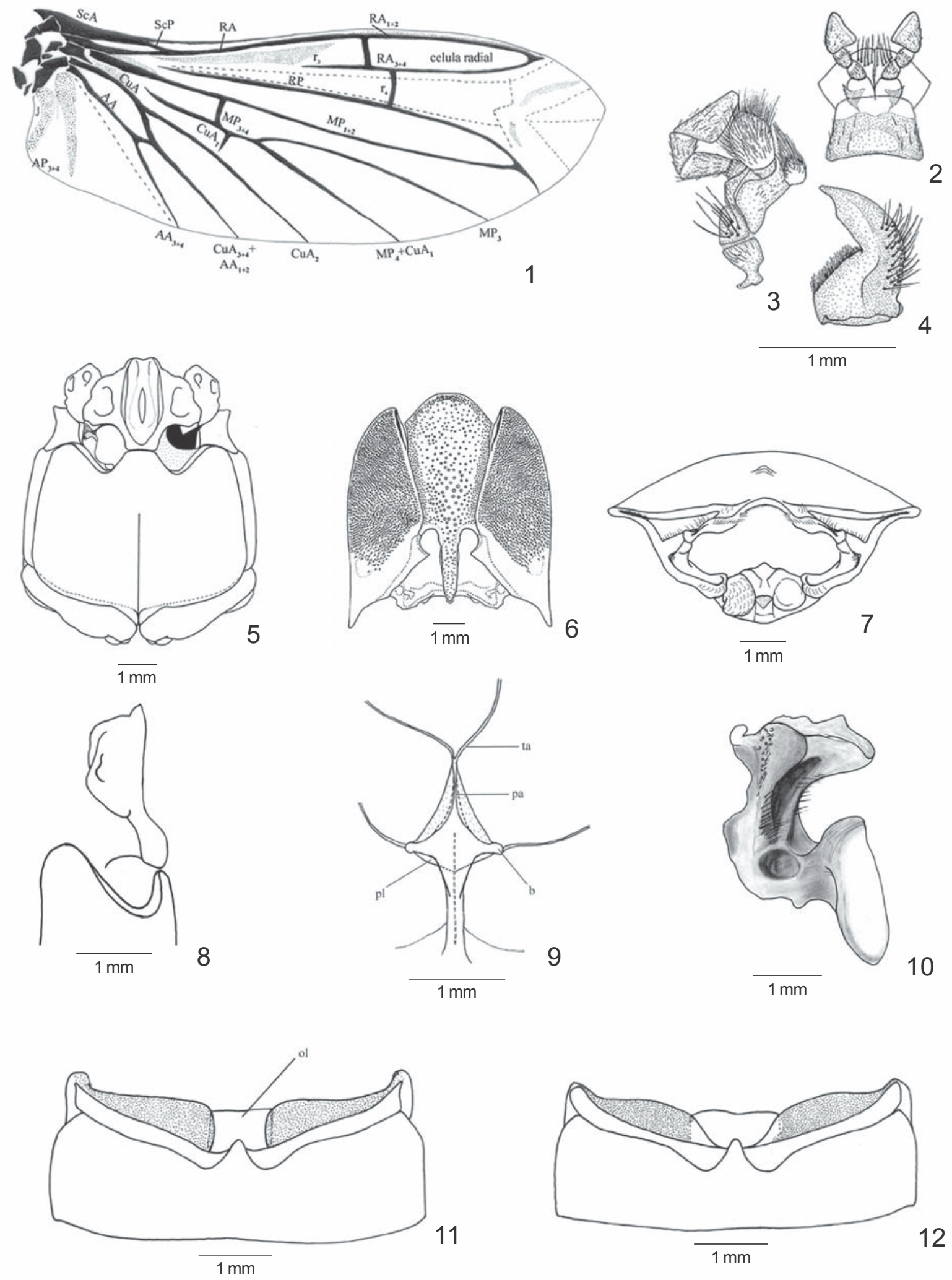

Figs. 1-12. Opselater costae sp. n. (macho): 1, asa; 2, lábio; 3, maxila direita (ventral); 4, mandíbula direita (dorsal); 5, pterotórax com mesocoxa esquerda removida (ventral); 6-7, protórax (ventral, posterior); 8, mesoventrito (lateral); 9, metendosternito; 10, escutelo e mesoscuto (lateral). O. pyrophanus (macho): 11, segmentos abdominais I-III. O. succinus (macho): 12, segmentos abdominais I-III. AA $=$ Anal anterior; AP $=$ Anal posterior; $\mathrm{b}=$ braço lateral; $\mathrm{CuA}=$ Cubital anterior; $\mathrm{J}=\mathrm{Jugal} ; \mathrm{MP}=$ Medial posterior; $\mathrm{ol}=$ órgão luminescente; $\mathrm{pa}=$ processo anterior; $\mathrm{pl}=$ processo látero-ventral; $\mathrm{r}=$ veia transversal; $\mathrm{RA}=$ Radial anterior; $\mathrm{RP}=$ Radial posterior; $\mathrm{ScA}=$ Subcosta anterior; $\mathrm{ScP}=\mathrm{Subcosta}$ posterior; ta $=$ tendão anterior. 
basal com margem anterior mais esclerotizada, quase reta a emarginada. Parâmeros mais curtos que o pênis, com carena látero-apical saliente; articulados ao esclerito dorsal do pênis na base, livres na face ventral. Pênis formado por um esclerito dorsal bem desenvolvido, com dois prologamentos basais, e um esclerito ventral mais estreito, alongado. Esclerito dorsal geralmente com margens laterais, próximas aos prolongamentos basais, com um abaulamento em cada lado, recobertos ou não por minúsculas escamas; superfície látero-ventral da região anterior ao ápice com ou sem pequenas escamas; esclerito ventral mais estreito, alongado, liso, com formato variável; prolongamentos basais com $1 / 4$ a $1 / 3$ do comprimento total do esclerito dorsal.

Fêmea. Geralmente maior que o macho, olhos um pouco menores, corpo mais convexo, lados do pronoto e élitros arredondados; antenas pouco ou muito mais curtas, fracamente serreadas. Genitália feminina. Tergito VIII (Fig. 31) com cerdas longas, uniformemente esclerotizado, com base quase reta e ápice arredondado. Esternito VIII (Fig. 32) com espículo alongado (1,4 vezes o comprimento do esternito), ápice arredondado, margens látero-distais e posterior com cerdas longas. Ovipositor (Figs. 28, 29) sem styli; coxitos parcialmente membranosos com ápices arredondados; parte membranosa interna revestida por pilosidade densa, fina e alongada, parte esclerotizada com cerdas longas, fortes e espaçadas; baculi tão longos quanto os coxitos, fortemente esclerotizados. Trato genital feminino (Figs. 28, 30). Região anterior da vagina alargada, com parede revestida por minúsculos espinhos e duas peças esclerotizadas e espinhosas, semitubulares, localizadas em cada lado da vagina, anteriores às glândulas coleteriais; glândulas coleteriais alongadas, membranosas, localizadas anteriormente ao oviduto comum; bursa copulatrix espiralada, com uma série de espinhos alongados; duas espermatecas presentes, longas, espiraladas apicalmente.

Dimensões (em mm). Comprimento total. Macho: 15,6-22,2; fêmea: 19,4-32,0. Comprimento do pronoto. Macho: 3,9-6,5, fêmea: 4,5-9,0. Largura do pronoto. Macho: 3,7-6,9; fềmea: 4,99,0. Largura umeral. Macho: 3,8-7,0; fêmea: 4,9-9,0. Comprimento dos élitros. Macho: 2,4-3,0 vezes o comprimento do pronoto; fêmea: 2,3-3,0 vezes o comprimento do pronoto.

Distribuição. Panamá, Guiana Francesa, Brasil, Peru, Bolívia, Paraguai e Argentina.

Comentários. As fêmeas das espécies de Opselater diferem dos machos, em geral, pelo tamanho maior, corpo mais convexo de lados arredondados e antenas mais curtas, e não apresentam diferenças específicas na genitália ou no trato genital. As fêmeas de $O$. helvolus e $O$. melanurus não são conhecidas. A única fêmea conhecida de $O$. quadraticollis é o tipo descrito por BLANCHARD (1843) e não foi analizado neste trabalho.

Baseado no estudo morfológico as espécies deste gênero podem ser separadas em dois grupos: A) Opselater melanurus,
$O$. hebes e $O$. succinus, caracterizadas principalmente pelas antenas com segundo e terceiro antenômeros de comprimento subiguais, órgão luminescente abdominal sub-retangular e esclerito dorsal do pênis com abaulamentos laterais mais alongados e proeminentes, e B) Opselater costae sp. nov., $O$. helvolus, O. lucens, O. pyrophanus e O. quadraticollis, caracterizadas pelas antenas com terceiro antenômero mais longo que o segundo, órgão luminescente abdominal subquadrangular e esclerito dorsal do pênis com abaulamentos laterais curtos e pouco proeminentes.

As espécies do grupo A são similares a algumas espécies do gênero Lygelater Costa, 1975 pela forma dos antenômeros e dos órgãos luminescentes do pronoto e do abdômen, e pela pontuação do pronoto e dos élitros. Diferem pelo tamanho menor e antenas mais curtas. Opselater lucens, O. helvolus e O. quadraticollis são semelhantes as espécies de Ignelater Costa, 1975 pela forma e coloração do pronoto e ápices dos élitros. Diferem pelas antenas mais curtas e vesículas luminescentes menores. O. costae e O. pyrophanus são similares às espécies de Deilelater Costa, 1975, pela forma, cor e pontuação do pronoto e pela forma das vesículas luminescentes. Diferem pelas antenas mais longas, vesículas luminescentes menores e élitros mais afilados.

Todas as espécies de Opselater podem ser separadas das espécies dos gêneros similares pelas seguintes características do edeago: esclerito dorsal do pênis geralmente com abaulamentos laterais menores, recobertos por minúsculas escamas; esclerito ventral liso. Os parâmeros do edeago, vistos dorsal ou ventralmente, parecem possuir um pequeno espinho látero-apical, tal como foi descrito por CosTA, 1980. No entanto, o exame dos edeagos em vista lateral demonstrou que se trata de uma pequena carena. Em outros gêneros de Pyrophorini os parâmeros podem apresentar carena semelhante a essa ou espinhos, de tamanhos variáveis.

\section{BIOLOGIA}

Assim como todos os Pyrophorini, as larvas de Opselater são predadoras, possuem digestão extra-oral e vivem no solo, sob madeira semi-apodrecida. Larvas de primeiro ínstar e madura de O. pyrophanus foram descritas por CASARI-CHEN \& Costa (1986). Elas não apresentam diferenças morfológicas significativas das larvas de outras espécies de Pyrophorina Costa, 1975 nem de Hapsodrilina Costa, 1975, mas diferem pela emissão de luz restrita à região do protórax, enquanto que as demais emitem luz também nos segmentos abdominais. Larvas das outras espécies desse gênero ainda são desconhecidas. Os adultos são noturnos e fitófagos.

Machos e fêmeas de Opselater pyrophanus e apenas um macho de $O$. lucens foram coletados em Ilha Comprida, no litoral sul do Estado de São Paulo. Os primeiros vaga-lumes apareceram por volta das 20 horas. Foram observados vários machos voando, emitindo luz continuamente por meio das vesículas luminescentes do pronoto. Algumas fêmeas foram observadas sobre a vegetação, emitindo luz durante curto intervalo de tempo (1-2 segundos) e repetindo o sinal luminoso 

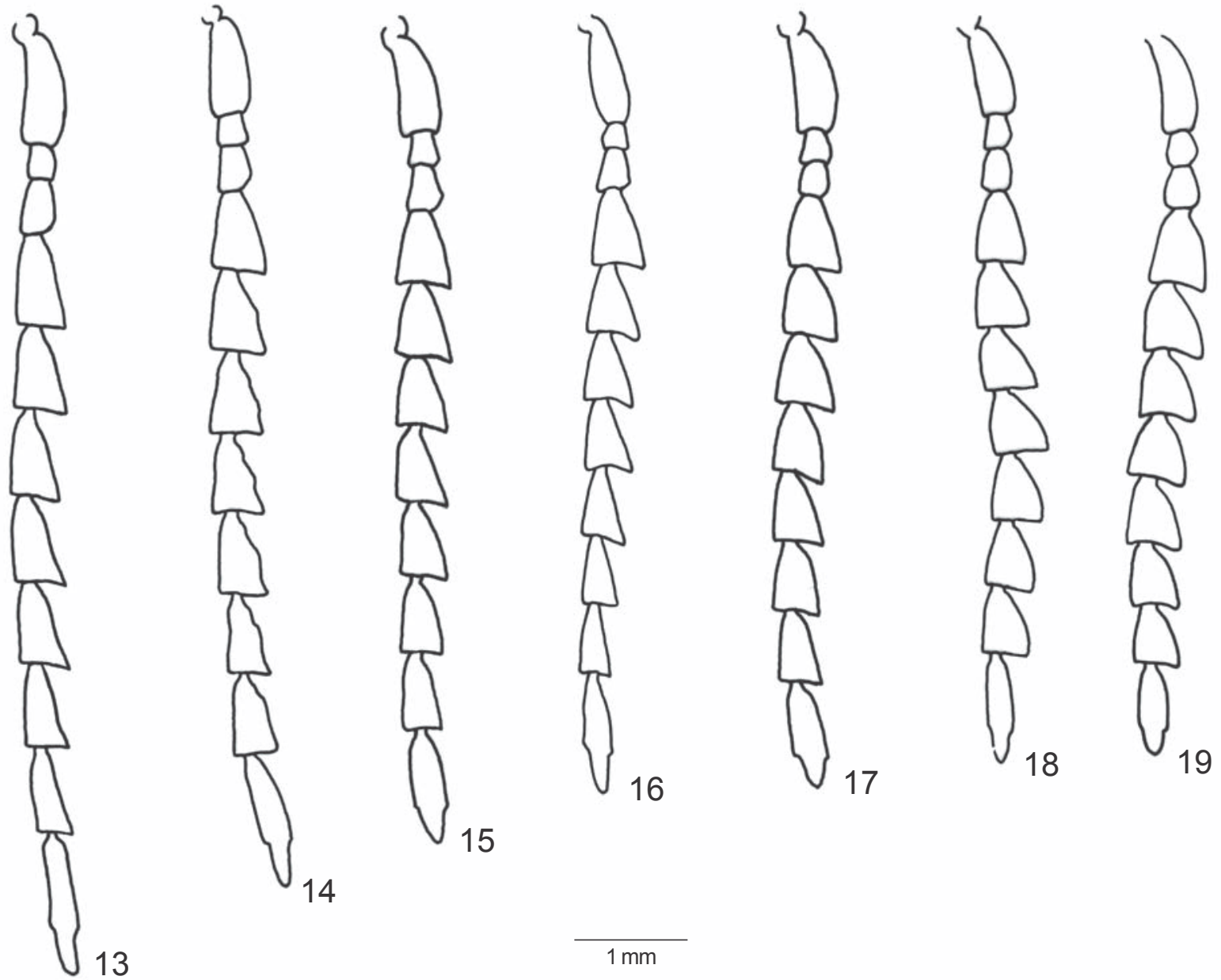

Figs. 13-19. Antena (macho): 13, Opselater pyrophanus; 14, O. costae sp. n.; 15, O. quadraticollis; 16, O. lucens; 17, O. succinus; 18, O. melanurus; 19, O. hebes.

de três a nove vezes consecutivas. A luz do órgão abdominal não era visível quando voavam, mas um ponto de luz nessa região podia ser visto quando o inseto perturbado, tentava saltar.

Com o objetivo de obter ovos e larvas, machos e fêmeas de $O$. pyrophanus destas coletas foram acondicionados em recipientes com substrato formado por terra, areia e pedaços de madeira. Foram mantidos em laboratório com temperatura controlada entre 25 e $30^{\circ} \mathrm{C}$ e alimentados com uma mistura de água e açúcar, colocada em algodão, e pedaços de laranja e uva. Durante o dia os insetos permaneciam imóveis, escondidos ou não sob os pedaços de madeira. À noite eram mais ativos, iluminando espontaneamente e sempre reunidos sobre os pedaços de fruta ou no algodão. As fêmeas morreram cerca de duas semanas após sua chegada no laboratório; os machos foram fixados após quatro semanas. O substrato foi observado, mas não foram encontrados ovos nem larvas.

Chave para as espécies de Opselater

1. Antenas com $4^{\circ}$ ao $10^{\circ}$ antenômeros curtos, fortemente serreados, $3^{\circ}$ antenômero subigual ao $2^{\circ}$ (Figs. 17-19)

Antenas com $4^{\circ}$ ao $10^{\circ}$ antenômeros curtos ou alongados, normalmente serreados, $3^{\circ}$ mais longo que o $2^{\circ}$. (Figs. 13-16) 3

2(1). Antenas com três primeiros antenômeros amarelados; pronoto com faixa longitudinal preta ou castanhoescura de largura aproximadamente igual a um terço da largura do pronoto ou com faixa amarelada nas margens laterais, duas vezes mais larga que o ângulo anterior; vesículas luminescentes geralmente ocultas sob a pilosidade; ápices dos élitros afilados 4

Antenas uniformemente pretas ou castanhas; pronoto com faixa amarelada nas margens laterais da mesma largura do ângulo anterior; vesículas luminescentes visíveis; ápices dos élitros conjuntamente arredondados (Fig. 57).

O. hebes (Germar, 1841)

3(1). Antenas uniformemente castanho-escuras ou pretas, geralmente quase do mesmo comprimento em machos 
e fêmeas; pronoto com pontuação fina, faixa longitudinal mediana preta ou castanho-escura; vesículas luminescentes pequenas, ovais e oblíquas (Figs. 25-27)

Antenas uniformemente amareladas ou com os três primeiros antenômeros amarelados, mais longas nos machos; pronoto de coloração uniforme, com pontuação média ou forte; vesículas luminescentes relativamente grandes, ovais e subparalelas (Figs. 23, 24)

4(2). Protórax de lados subparalelos; pronoto com faixa amarelada nas margens laterais, duas vezes mais larga que o ângulo anterior, ângulos posteriores fracamente carenados; élitros com a metade anterior amarelada (Fig. 61) …………….... O. melanurus (Candèze, 1863)

Protórax de lados levemente arredondados; pronoto com faixa longitudinal mediana preta ou castanho-escura de largura aproximadamente igual a um terço da largura do pronoto, ângulos posteriores carenados; élitros uniformemente coloridos (Fig. 62)

.. . succinus Costa, 1980

5(3). Lados do pronoto arredondados, ângulos posteriores curtos, fortes (Figs. 25, 60) ...... O. lucens (Illiger, 1807)

Lados do pronoto subparalelos, ângulos posteriores alongados, delgados (Figs. 26, 27) .

6(3). Antenas uniformemente amareladas em ambos os sexos, nos machos ultrapassando os ângulos posteriores do pronoto a partir do $9^{\circ}$ ou $10^{\circ}$ antenômero; epipleuras castanhas; pronoto pouco convexo de lados subparalelos, pontuação média, moderadamente densa, ângulos posteriores fracamente carenados (Figs. 24, 59) ..................... O. pyrophanus (Illiger, 1807)

Antenas com três primeiros antenômeros amarelados no macho, uniformemente amareladas na fêmea, nos machos geralmente ultrapassando os ângulos posteriores a partir do $11^{\circ}$ antenômero; epipleuras amareladas; pronoto regularmente convexo de lados levemente arredondados, pontuação forte e densa, ângulos posteriores carenados (Figs. 23, 58)

O. costae $\mathbf{s p . ~ n o v . ~}$

7(5). Antenas não ultrapassam os ângulos posteriores do pronoto; élitros com strigae fortemente marcadas, ápices afilados ..................... O. helvolus (Germar, 1841)

Antenas ultrapassam os ângulos posteriores do pronoto (Fig. 25); élitros com strigae fracamente marcadas, ápices mucronados (Fig. 56) ... O. quadraticollis (Blanchard, 1843)

Opselater costae sp. nov.

(Figs. 1-10, 14, 23, 39-41, 58)

Macho. Tegumento de coloração geral (Fig. 58) castanha a castanho-escura. Antenas geralmente castanho-escuras, exceto três primeiros antenômeros castanho-claros. Pernas e hipômeros, geralmente, da mesma cor do tegumento. Epipleuras amareladas. Pronoto uniformemente colorido, raramente com faixa longitudinal mediana mais escura, de largura aproximadamente igual a um terço da largura total do pronoto. Élitros uniformemente coloridos. Pilosidade curta, densa, amarela.

Fronte côncava, com pontuação densa, média e umbilicada. Antenas (Fig. 14) geralmente ultrapassando os ângulos posteriores do pronoto a partir do $11^{\circ}$ antenômero; $4^{\circ}$ ao $10^{\circ}$ antenômeros alongados e normalmente serreados; $3^{\circ}$ antenômero mais longo (1,44 vezes) que o $2^{\circ}$.

Protórax com lados levemente arredondados. Pronoto (Figs. $7,23)$ regularmente convexo com pontuação forte, simples e densa na região discal; densa e umbilicada nas margens laterais. Vesículas luminescentes visíveis, relativamente grandes, ovais, subparalelas. Ângulos posteriores delgados, carenados e pouco divergentes. Prosterno (Fig. 6) com pontuação média e espaçada no processo prosternal; fina e densa nas margens laterais; média ou forte e espaçada a densa, da região anterior ao processo prosternal até a mentoneira. Hipômeros com pontuação fina.

Órgão luminescente abdominal subquadrangular.

Élitros com strigae fortemente marcadas; interestrias achatadas, com pontuação fina e moderadamente densa; ápices afilados, pouco deiscentes.

Edeago (Figs. 39-41). Pênis. Esclerito dorsal com lados subparalelos até o ápice abruptamente afilado; abaulamentos laterais muito curtos e pouco proeminentes; superfície láteroventral da região anterior ao ápice com minúsculas escamas. Esclerito ventral com o 1/5 basal um pouco mais estreito, lados divergentes até o $1 / 4$ posterior duas vezes mais largo que a base, convergentes até o ápice emarginado.

Fêmea. Faixa longitudinal mediana do pronoto geralmente mais escura; antenas mais curtas, uniformemente amareladas e fracamente serreadas.

Dimensões (mm). Comprimento total. Macho: 18,8-22,4; fêmea: 20,5-30,0. Comprimento do pronoto. Macho: 4,3-5,7; fêmea: 5,4-7,5. Largura do pronoto. Macho: 4,6-5,5; fêmea: 5,7-7,5. Largura umeral. Macho: 4,0-5,7; fêmea: 5,5-7,7. Comprimento dos élitros. Macho: 2,7-3,0 vezes o comprimento do pronoto; fêmea: 2,5-2,7 vezes o comprimento do pronoto.

Distribuição. Brasil (Espírito Santo).

Holótipo (macho), BRASIL. Espírito Santo: Linhares. XI.1972 (P. C. Elias) (MZSP). Parátipos: idem, 22 machos, 21 fêmeas; idem, 4.III.1988 (J. S. Santos), 2 fêmeas (MZSP); idem,10.XI.1987 (J. S. Santos), 1 fêmea (MZSP); idem, 5.v.1987 (J. S. Santos), 1 macho (MZSP); idem, 22.I.1988 (J. S. Santos), 1 fêmea (MZSP); idem, 18.IX.1990 (J. S. Santos), 1 fêmea (MZSP); idem, XII.1972 (P. C. Elias), 4 machos, 7 fêmeas (MZSP); idem, I.1972 (P. C. Elias), 1 fêmea, 1 fêmea (MZSP); idem, IX.1970 (B. Silva), 1 fêmea (MNRJ); idem, 30.XI.1974 (C. S. Carbonell), 1 fêmea (MZSP); idem, XI.1960 (D. Zajclw), 1 fêmea (MZSP); idem, X.1969 (M. Morais), 1 fêmea (MZSP); Colatina, XII.1970 (A. Silva), 1 fêmea (MZSP). 

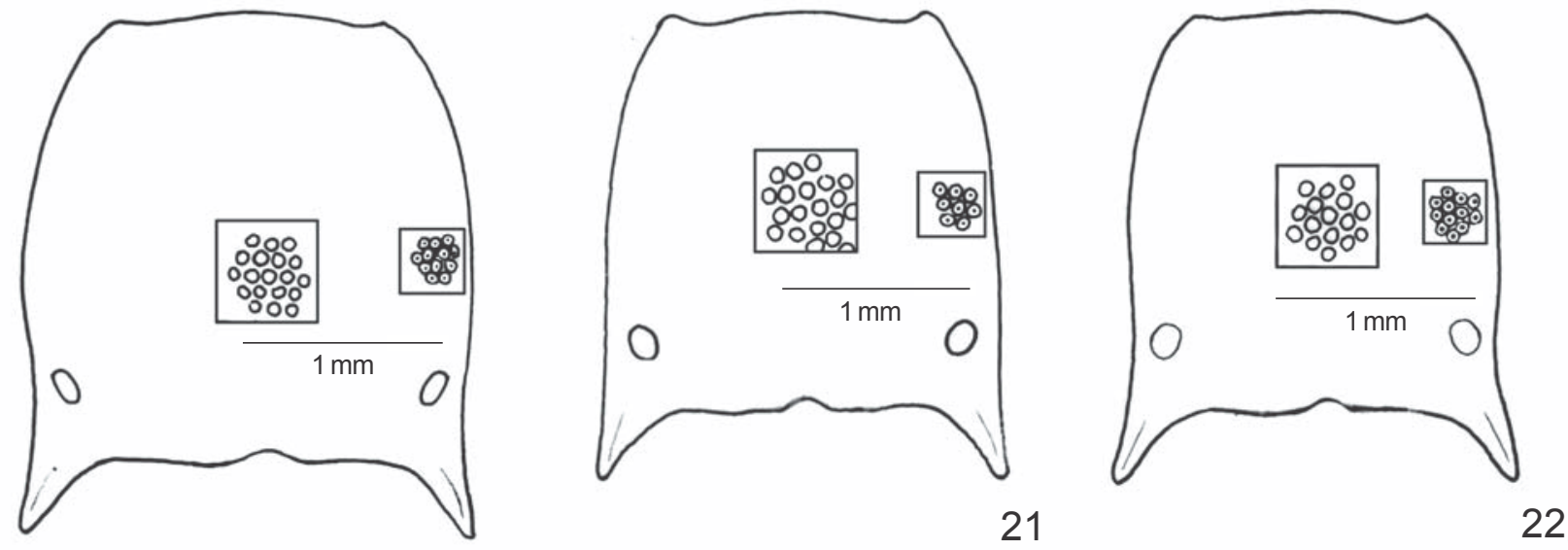

20

$\overline{1 \mathrm{~mm}}$
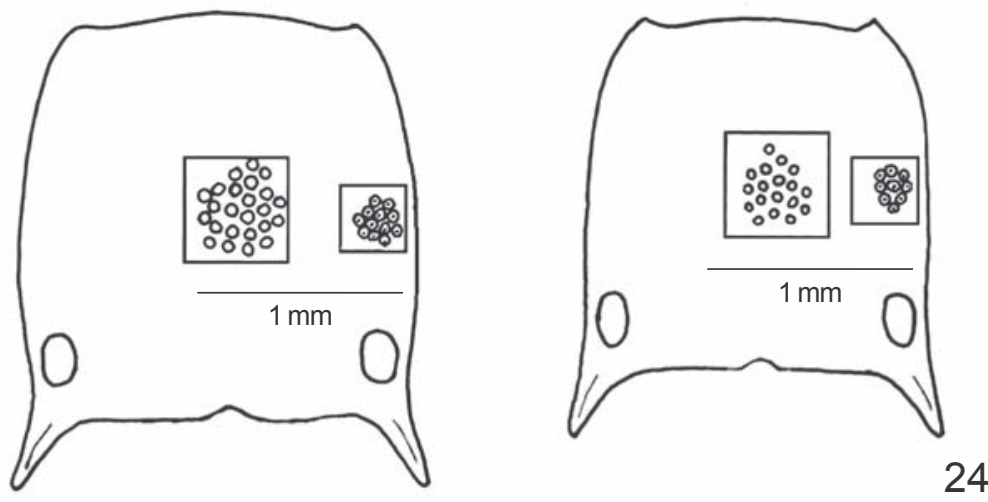

23
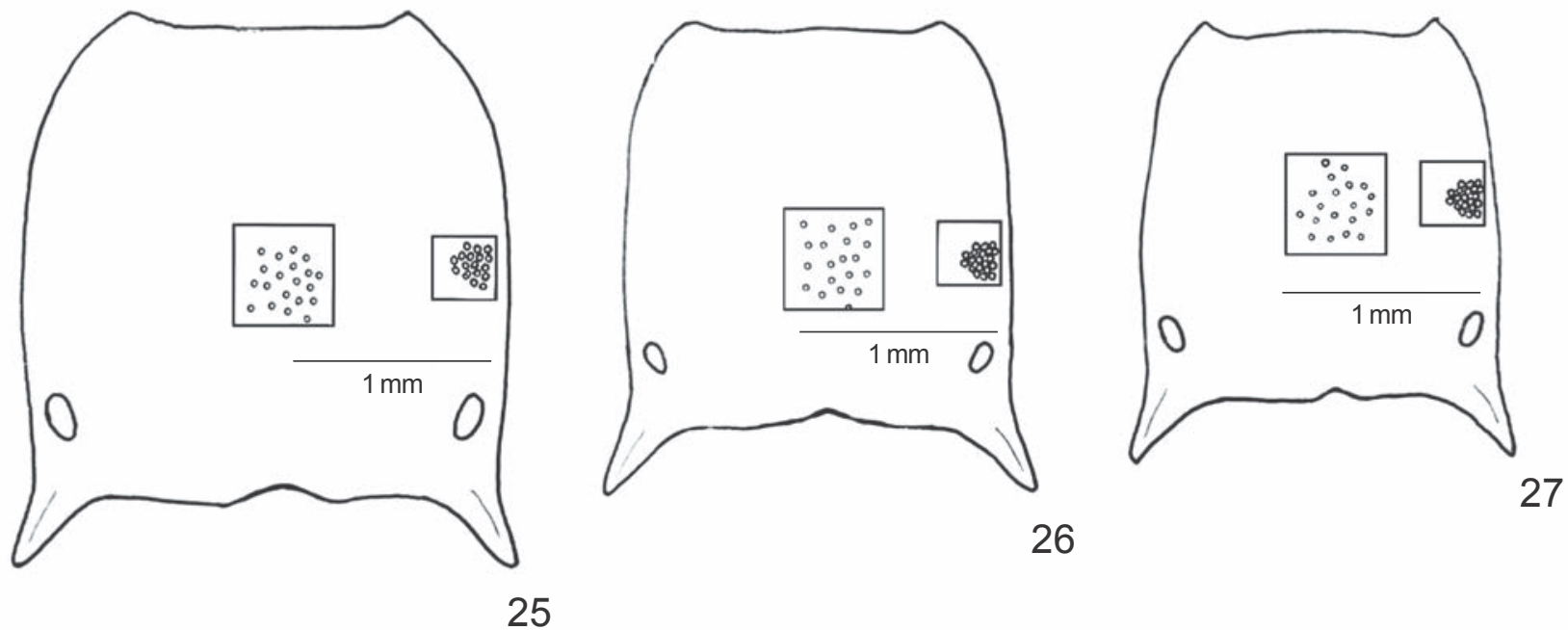

25

$1 \mathrm{~mm}$

Figs. 20-27. Pronoto (macho): 20, Opselater succinus; 21, O. hebes; 22, O. melanurus; 23, O. costae sp. n.; 24, O. pyrophanus; 25, O. lucens; 26, O. quadraticollis; 27, O. helvolus. 
Comentários. Opselater costae sp. nov. assemelha-se a $O$. pyrophanus pela coloração do corpo, forma das vesículas luminescentes e das antenas, mas difere pelo corpo mais robusto e convexo, pela pontuação do pronoto maior e mais densa, antenas geralmente mais curtas e com os três primeiros antenômeros amarelados nos machos, e por apresentar edeago com pênis mais largo.

Etimologia. Homenagem à pesquisadora Cleide Costa, por sua importante contribuição ao estudo dos Pyrophorini.

\section{Opselater hebes (Germar, 1841)}

(Figs.19, 21, 46, 47, 57)

Pyrophorus hebes Germar, 1841: 27 (desc.). Lectótipo macho. Brasil. Minas Gerais: São João del Rey (ZMHB) (não examinado). Candèze, 1863: 35 (syn. com P. coecus Germar, 1841); Schenkling, 1927: 350 (in syn., cat.) Blackwelder, 1944: 285 (in syn., cat.).

Opselater hebes; Costa, 1975:104, figs. 37, 37a (reval.); 1980: 165, fig. 16 (chave, redesc., designação do lectótipo).

Pyrophorus lusciosus Germar, 1841: 39 (desc.). Localidade-tipo: Bahia. Candèze, 1863:30 (rev.); Schenkling, 1927: 354 (cat.); Blackwelder, 1944: 286 (cat.); Costa, 1975: 104 (syn.).

Macho. Tegumento de coloração geral (Fig. 57) castanhoescura. Antenas pretas ou castanho-escuras, raramente com os três primeiros antenômeros mais claros. Pernas geralmente da mesma cor do tegumento. Hipômeros e epipleuras amarelados ou castanhos mais claros que a cor geral do tegumento. Pronoto com faixa amarelada nas margens laterais da mesma largura do ângulo anterior. Élitros uniformemente coloridos ou com margem anterior castanho-avermelhada. Pilosidade curta, densa, amarela.

Fronte quase plana, com pontuação, densa, forte e umbilicada. Antenas (Fig. 19) não ultrapassam os ângulos posteriores do pronoto; $4^{\circ}$ ao $10^{\circ}$ antenômeros curtos e fortemente serreados; $3^{\circ}$ antenômero com comprimento subigual $(1,2$ vezes $)$ ao do $2^{\circ}$.

Protórax com lados subparalelos. Pronoto (Fig. 21) regularmente convexo com pontuação forte, simples e densa na região discal; densa e umbilicada nas margens laterais. Vesículas luminescentes geralmente visíveis, pequenas e arredondadas, raramente ovais e oblíquas, convergentes posteriormente. Ângulos posteriores fortes, fracamente carenados e dirigidos para trás. Prosterno com pontuação fina e espaçada no processo prosternal; forte e densa nas margens laterais; forte, moderadamente densa a densa, da região anterior ao processo prosternal até a mentoneira. Hipômeros com pontuação média.

Órgão luminescente abdominal sub-retangular.

Élitros com strigae fortemente marcadas; interestrias achatadas, com pontuação fina e moderadamente densa; ápices conjuntamente arredondados, pouco deiscentes.

Edeago (Figs. 46, 47). Pênis. Esclerito dorsal com lados sinuosos e ápice gradualmente afilado; abaulamentos laterais alongados e muito proeminentes; superfície látero-ventral da região anterior ao ápice lisa. Esclerito ventral com base arredondada, lados subparalelos nos $2 / 3$ basais e gradualmente afilados para o ápice no $1 / 3$ posterior; ápice arredondado ou levemente emarginado.

Dimensões (em mm). Comprimento total. Macho: 18,5-21,6; fêmea: 18-21,2. Comprimento do pronoto. Macho: 5,0-5,4; fêmea: 5,0-6,0. Largura do pronoto. Macho: 4,9-5,4; fêmea: 4,5-5,3. Largura umeral. Macho: 4,9-5,5; fêmea: 4,4-5,5. Comprimento dos élitros. Macho: 2,5-2,7 vezes o comprimento do pronoto; fêmea: $2,4-2,5$ vezes o comprimento dos élitros.

Distribuição. Brasil (Pará, Tocantins, Goiás, Minas Gerais, São Paulo).

Material examinado. BRASIL. Sem localidade, sem data (sem coletor) 1 ex. (Candèze det.) (MNHN). Pará: Fazenda Taperinha, prox. Santarém, 29.XII.1967-9.I.1968 (Exp. Perm. Amaz.), 1 ex (MZSP); Santarém, I.1878 (M. de Mathan), 1 ex. (MNHN). Tocantins: Palmas, $5^{\text {a }}$ do Lageado, Fazenda Céu, XI.1992, 1 ex. (MCNZ). Goiás: sem localidade, sem data, sem coletor, 1 ex. (coll. Candèze) (ISNB). Minas Gerais: S. João del Rei, sem data, sem coletor, 1 ex. (coll. Camille Van Voixem) (ISNB); Passos, 10-15.XII.1962 (Claudionor Elias), 1 ex. (DZUP). São Paulo: Ipiranga, sem data, sem coletor, 1 ex. (MZSP).

Comentários. Os exemplares estudados apresentam grande variação; alguns são pequenos, possuem élitros com região anterior mais clara e os três primeiros antenômeros amarelos tal como O. melanurus (Candèze, 1863), outros têm corpo uniformemente castanho-escuro, bastante alongado. São muito semelhantes a $O$. melanurus na pontuação e convexidade do pronoto, na forma das antenas e do edeago, mas diferem pela coloração do corpo, geralmente castanho-escura com uma estreita faixa amarelada nas margens laterais do pronoto.

Opselater helvolus (Germar, 1841)

(Figs.27, 44, 45)

Pyrophorus helvolus Germar, 1841: 28 (desc.). Lectótipo macho, Brasil. Bahia, no 43385 (ZMHB) (não examinado). Candèze, 1863: 32 (syn. com P. illuminans Germar, 1841); Schenkling, 1927: 351 (in syn., cat.); Blackwelder, 1944: 285 (in syn., cat.).

Opselater helvolus; Costa, 1975: 104 (reval.); 1980: 166, figs. 13, 19 (chave, redesc., designação do lectótipo).

Pyrophorus pyralis (parte) Germar, 1841: 35 (desc.). Localidade-tipo: “America Meridionalis". Costa, 1975: 104 (syn.).

Macho. Tegumento de coloração geral castanho-clara. Antenas castanhas. Hipômeros e epipleuras amarelados, mais claros que a cor geral do tegumento. Pronoto com faixa longitudinal mediana castanha mais escura que as margens laterais, de largura aproximadamente igual a um terço da largura total do pronoto. Élitros uniformemente coloridos. Pilosidade curta, densa, fina e acizentada.

Fronte côncava, com pontuação densa, fina e umbilicada. Antenas não ultrapassam os ângulos posteriores do pronoto; $4^{\circ}$ ao $10^{\circ}$ antenômeros alongados e normalmente serreados; $3^{\circ}$ antenômero mais longo ( 1,6 vezes) que o $2^{\circ}$.

Protórax com lados subparalelos. Pronoto (Fig. 27) pouco convexo com pontuação fina, simples e moderadamente densa na região discal; densa e umbilicada nas margens laterais. Vesículas luminescentes visíveis, pequenas, ovais e oblíquas, convergentes posteriormente. Ângulos posteriores delgados, 

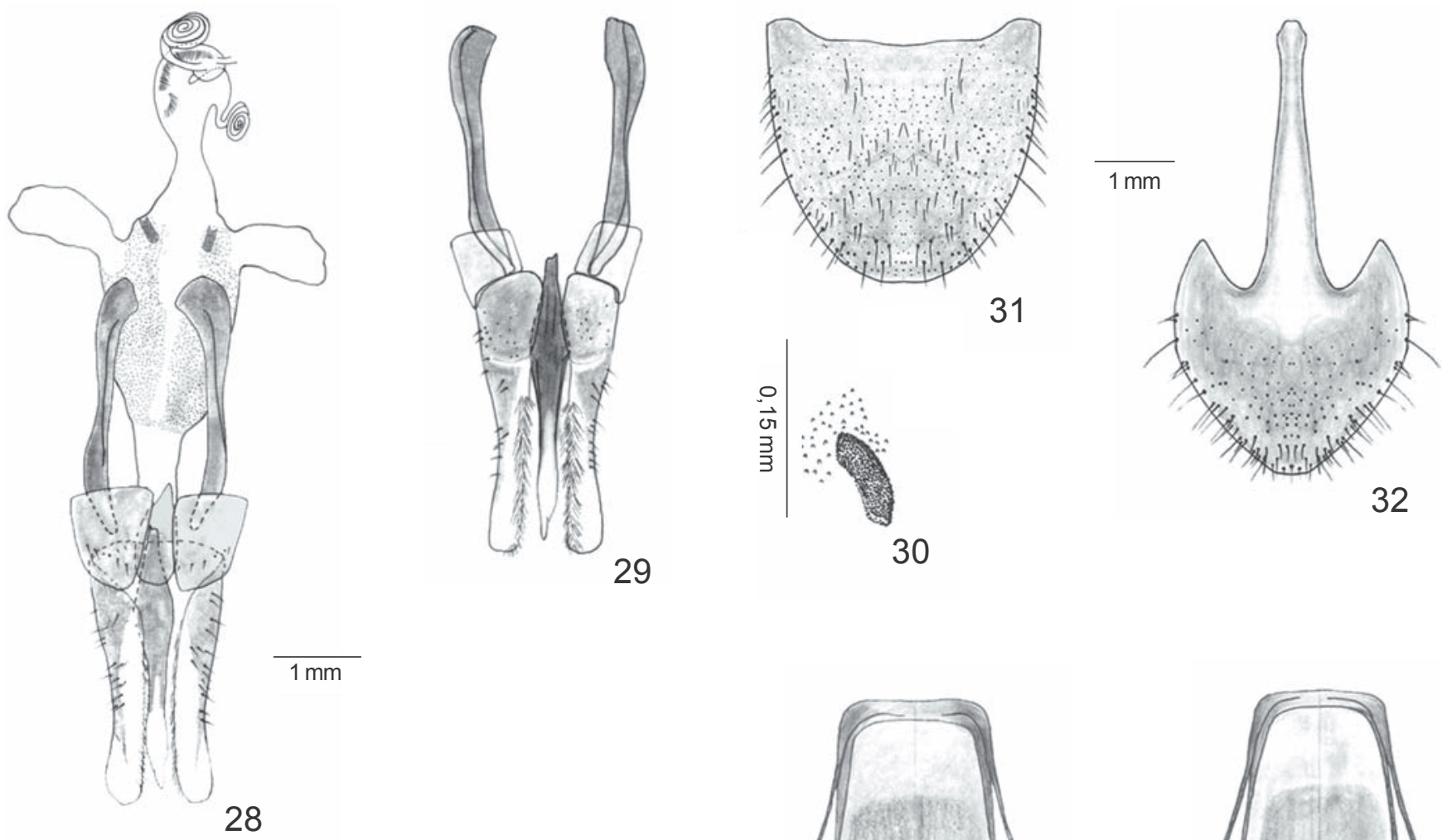

29

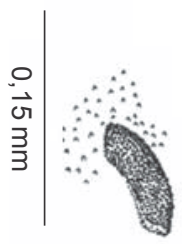

31

30

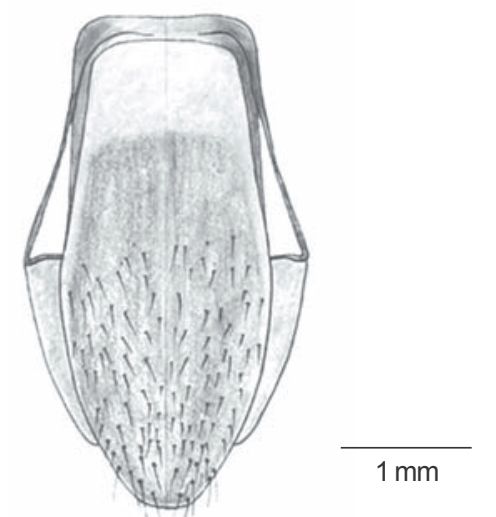

35

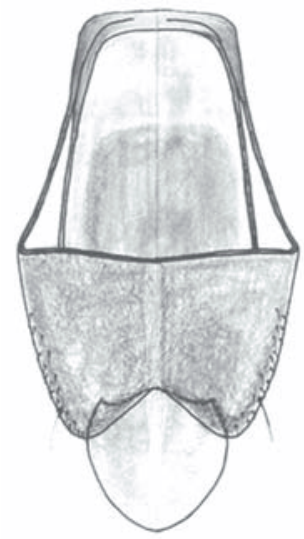

36

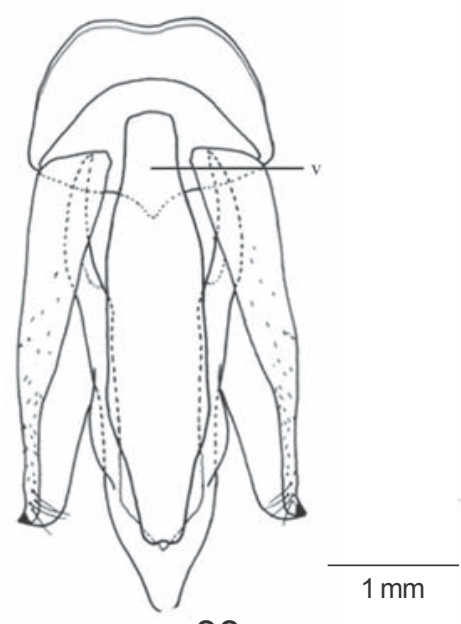

33

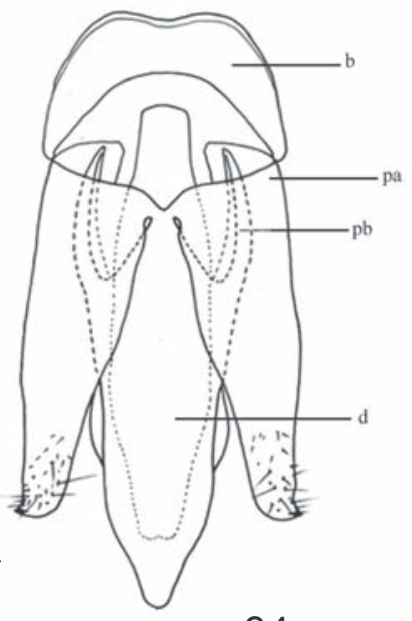

34

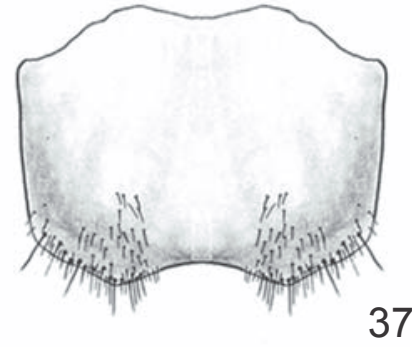

37

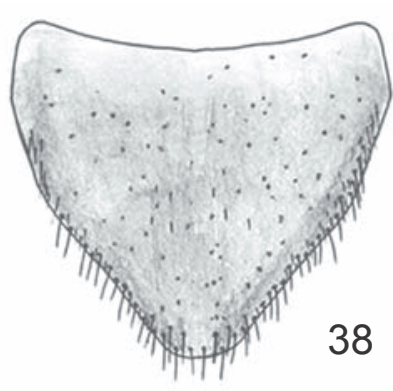

38

Figs. 28-38. Opselater pyrophanus (fêmea): 28, ovipositor e trato genital (ventral); 29, ovipositor (dorsal); 30, peça esclerotinizada da vagina; 31, tergito VIII; 32, esternito VIII. O. pyrophanus (macho): 33, 34, edeago (ventral, dorsal); 35, esternito IX; 36, tergitos IX e X; 37, esternito VIII; 38, tergito VIII. $\mathrm{b}=$ peça basal; $\mathrm{d}=$ esclerito dorsal do pênis; $\mathrm{v}=$ esclerito ventral do pênis; $\mathrm{pa}=$ parâmero; $\mathrm{pb}=$ prolongamento basal do esclerito dorsal. 
carenados e divergentes. Prosterno com pontuação fina e espaçada no processo prosternal; fina e densa nas margens laterais; média, moderadamente densa da região anterior ao processo prosternal até a mentoneira. Hipômeros com pontuação fina.

Órgão luminescente abdominal subquadrangular.

Élitros com strigae fortemente marcadas, interestrias achatadas, com pontuação muito fina e moderadamente densa; ápices afilados, deiscentes.

Edeago (Figs. 44, 45). Pênis. Esclerito dorsal com lados gradualmente afilados para o ápice; abaulamentos laterais curtos e pouco proeminentes; superfície látero-ventral da região anterior ao ápice lisa. Esclerito ventral com lados levemente arredondados, com uma constricção anterior, na altura das bases dos parâmeros; ápice levemente alargado e truncado.

Dimensões (em mm). Comprimento total. 17,0. Comprimento do pronoto. 4,5. Largura do pronoto. 4,5. Largura umeral. 4,0. Comprimento dos élitros. 2,5 vezes o comprimento do pronoto.

Distribuição (segundo Costa 1980). BRASIL (Bahia, Espírito Santo)

Material examinado. BRASIL. Sem localidade, 1815 (A. St. Hilaire), 1 ex. (MNHN).

Comentários. O único exemplar de $O$. helvolus examinado não está completamente ilustrado neste trabalho porque apresenta as pernas e as antenas quebradas. A cor, a forma e a pontuação do pronoto e dos élitros conferem com a descrição de Costa (1980), que examinou os síntipos, no entanto o edeago deste exemplar é diferente daquele que foi ilustrado pela autora. No momento é apresentada a descrição e a ilustração do edeago deste único exemplar, que ainda deverá ser comparado com o tipo para confirmar sua identidade. É muito semelhante a $O$. lucens, do qual difere apenas pelo pronoto de lados subparalelos e por caracteres da genitália masculina.

\section{Opselater lucens (Illiger, 1807)}

(Figs.16, 25, 42, 43, 60)

Elater lucens Illiger, 1807: 150 (desc.). Lectótipo macho. Brasil. Bahia, Gomes col., n 17136 (ZMHB) (não examinado).

Pyrophorus lucens; Germar, 1841: 34 (rev.); Candèze, 1863: 30 (syn. com P. pyrophanus Illiger); Blackwelder, 1944: 286 (in syn. cat.).

Opselater lucens; Costa, 1975: 104, figs. 48, 48a, 168 (reval.); 1980: 167, figs. 8, 9, 10 (chave, redesc., designação do lectótipo); Golbach, 1994: 43 (cat.).

Pyrophorus illuminans (parte) Germar, 1841: 30 (desc.). Localidadetipo: Brasil. Candèze, 1863: 32 (rev.); Schenkling, 1927: 351 (cat.) Costa, 1975: 104 (syn.).

Pyrophorus fulvotomentosus Blanchard, 1843: 139 (desc.). Localidadetipo: Argentina: Corrientes. Candèze, 1863: 32 (syn.); Schenkling 1927: 351 (in syn., cat.); Blackwelder 1944: 285 (in syn., cat.).

Pyrophorus obscuratus Germar, 1841: 23 (desc). Localidade-tipo: Brasil. Costa, 1975: 104 (syn.).

Pyrophorus rufofuscus Sturm, 1843: 67 (desc.). Localidade-tipo: Brasil. Candèze, 1891 (syn.); Schenkling, 1927: 351 (in syn., cat.); Blackwelder, 1944: 285 (in syn., cat.); Costa, 1980: 167 (in syn.).

Pyrophorus lychniferus (parte) Germar, 1841: 32 (desc.) Localidadetipo: Brasil. Costa, 1980: 167 (syn.).
Macho. Tegumento de coloração geral (Fig.60) castanhoclara a castanho-escura, ou castanho-amarelada a castanhoavermelhada. Antenas castanhas ou castanho-escuras. Pernas geralmente da mesma cor do tegumento. Hipômeros e epipleuras amarelados ou castanhos mais claros que a cor geral do tegumento. Pronoto com faixa longitudinal mediana preta ou castanha mais escura que as margens laterais, de largura aproximadamente igual a um terço da largura total do pronoto. Élitros uniformemente coloridos. Pilosidade curta, densa, amarelo-clara a amarela.

Fronte côncava, com pontuação densa, fina e umbilicada. Antenas (Fig. 16) não ultrapassam os ângulos posteriores do pronoto; $4^{\circ}$ ao $10^{\circ}$ antenômeros curtos e normalmente serreados; $3^{\circ}$ antenômero mais longo (1,5 vezes) que o $2^{\circ}$.

Protórax com lados arredondados. Pronoto (Fig. 25) pouco convexo com pontuação fina, simples e moderadamente densa na região discal, densa e umbilicada nas margens laterais. Vesículas luminescentes visíveis, pequenas, ovais e oblíquas, convergentes posteriormente. Ângulos posteriores curtos, fortes, carenados e divergentes. Prosterno com pontuação fina e espaçada no processo prosternal; fina e densa nas margens laterais; média, moderadamente densa da região anterior ao processo prosternal até a mentoneira. Hipômeros com pontuação fina.

Órgão luminescente abdominal subquadrangular.

Élitros com strigae fracamente marcadas; interestrias achatadas, com pontuação muito fina e moderadamente densa; ápices mucronados, deiscentes.

Edeago (Figs. 42, 43). Pênis. Esclerito dorsal com lados sinuosos e ápice abruptamente afilado; abaulamentos laterais curtos e pouco proeminentes; superfície látero-ventral da região anterior ao ápice com minúsculas escamas; esclerito ventral com base um pouco mais estreita, lados subparalelos até o ápice truncado, geralmente não emarginado.

Fêmea. Difere pouco do macho, exceto pelas antenas um pouco mais mais curtas e menos serreadas.

Dimensões (em mm). Comprimento total. Macho: 20,0-20,7; fêmea: 23,0-30,0. Comprimento do pronoto. Macho: 5,2-6,5; fêmea: 5,7-7,8. Largura do pronoto. Macho: 5,3-6,9; fêmea: 5,7-8,2. Largura umeral. Macho: 5,2-7,0; fêmea: 6,0-8,1. Comprimento dos élitros. Macho: 2,5-2,9 vezes o comprimento do pronoto; fêmea: 2,5-2,7 vezes o comprimento do pronoto.

Distribuição. Panamá, Guiana Francesa (Cayenne), Brasil (Pará, Goiás, Bahia, Espírito Santo, Rio de Janeiro, Minas Gerais, São Paulo, Santa Catarina, Rio Grande do Sul), Paraguai, Argentina.

Material examinado: Sem país, sem localidade, sem data, sem coletor, 1 ex. (3398) (IBSP); idem, 1 ex. (MZSP); idem, 1 ex. (19083) (MZHF); idem, 2 ex. (coll. Kraatz) (DEIC); idem, 1 ex. (Chevrolat) (MNHN); idem, 1 ex. (MNRJ); idem, 1 ex. (coll. Oberthur) (MNHN); idem, 1 ex. (MNHN); idem, 1 ex. (coll. Schwarz) DEIC). PANAMÁ, sem localidade, 1883 (R. de Mente), 1ex. (ISNB). GUIANA FRANCESA. Cayenne, sem data, sem coletor, 1ex. (Col. Jekel, MNHN); idem, 1 ex. (Col. Alluaud) (DEIC). BRASIL. Sem localidade, sem data, sem coletor, 3 exs., (Col. Schwarz) DEIC); idem, 1ex. (MNHN); idem, 1ex. (MNHN); idem; 1ex. (MNHN); idem, 3 exs. (Col. Candèze) (ISNB); idem, 2 exs. 

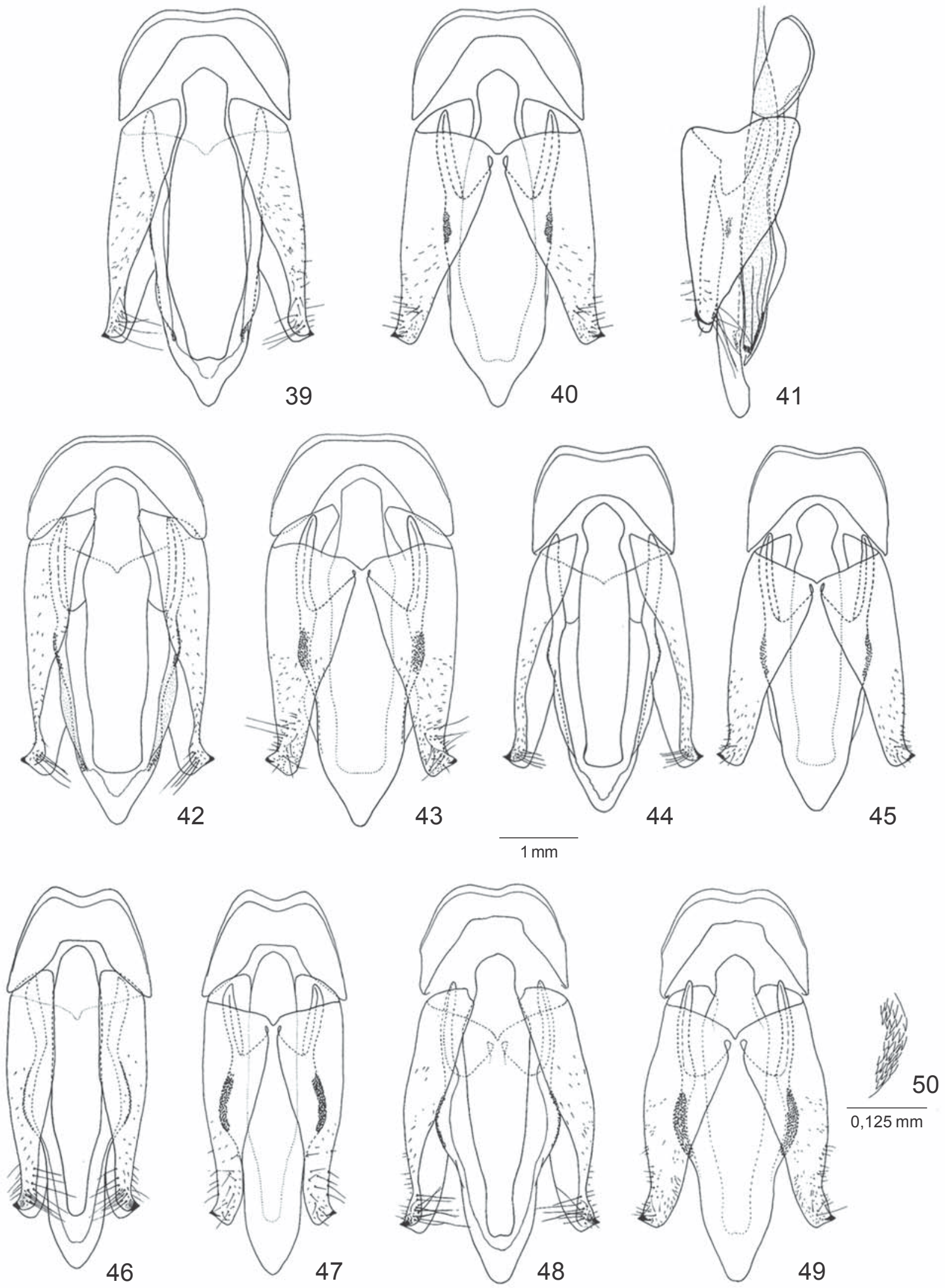

Figs. 39-50. Edeagos. Opselater costae sp. n.: 39, 40, 41, ventral, dorsal, lateral. O. lucens: 42, 43, ventral, dorsal. O. helvolus: 44, 45, ventral, dorsal. O. hebes: 46, 47, ventral, dorsal. O. melanurus: 48, 49, ventral, dorsal; 50, escamas do esclerito dorsal do pênis. 
(Col. Janson) (BMNH); idem, 1ex. (MNHN); idem, 3 exs. (coll. Hising) (MZHF); idem, 1 ex. (coll. Karl Brancsik 1955) (FMNH); idem, 1 ex. (MNHN); idem, 1 ex.(macho, parátipo de O. succinus) (Westermann) (ZMUC); idem, 1 ex. (MNHN); idem, 1 ex. (Hoffman coll, MNHN); sem localidade, 1833 (Gaudichaud), 1 ex. (MZSP). Pará: Oriximiná, cidade, 8.IX.1968 (P. Eleres), 1ex. ( MZSP); (Riv. Tapajós), 1883, sem coletor, 2 exs. (MNHN). Goiás: Anápolis, Chácara Tangará, 24.II.1966 (F. Lane), 1ex. (MZSP). Bahia: Itabuna, 10.xII.1968 (P. E. Vanzolini), 1 (MZSP); Água Preta, sem data (P. Silva), 1ex.(macho, parátipo de $O$. succinus) (L425B, IBSP); Ilhéus, Faz. São Caetano, sem data, sem coletor, 2 exs. (col. Dirings, MZSP); sem localidade, sem data, sem coletor, 1 ex. (col. Fleutiaux; MNHN), idem, sem data (Luschuath), 1ex. (MNHN). Espírito Santo: Linhares, X.1970 (B. Silva), 1 ex. (MZSP); idem, 05.IV.1988 (J. S. Santos), 1 ex. (MZSP); idem, X.1972 (PC. Elias), 1ex (MZSP); Santa Leopoldina, sem data, sem coletor, 1 ex. (MNHN); sem localidade, 1955, sem coletor, 1ex. (FMNH). Rio de Janeiro: Alto da Boa Vista, Tijuca, 1.I.1951 (C. A. C. Seabra), 1 ex. (MNRJ); Corcovado, III.1965 (Alvarenga e Seabra) 1ex., (MNRJ); Floresta da Tijuca, 14.III.1958 (C. A. C. Seabra), 1ex. (MNRJ); Nova Friburgo, sem data, sem coletor, 1 ex. (MNHN); sem localidade, 1844 (De Catelnau), 2 ex. (MNHN); idem, sem data, sem coletor, 1 ex. (MNHN). idem, sem data (Dr. Korber), 1 ex. (MNHN); Mendes, a 92 Km do Rio de Janeiro, sem data, sem coletor, 4 exs. (coll. Le Moult) (ISNB). Minas Gerais: Mariana, sem data, sem coletor, 1 ex. ( MZSP); Pratápolis, 05.XI.1963 (Claudionor Elias), 1ex. (DZUFP); sem localidade, VII.47 (De Castelnau), 1ex. (MNHN). São Paulo: Rio Piracicaba, II.1885 (P. Germain), 2 exs. (MNHN); Campinas, Estrada de Goiás, sem data, sem coletor, 1 ex. (Col. Dirings, MZSP); Franca, 1925, sem coletor, 1 ex. (DZUP); Ilha de São Sebastião, 17.XII.1953 (E. Urban), 1 ex. (IBSP); Itanhaem, 31.I.1968 (U.R. Martins), 1 ex. (MZSP); idem, sem data, sem coletor, 1 ex. ( col. Dirings) (MZSP); Peruíbe, 7.I.1938, sem coletor, 4 exs. (MNRJ); Ilha Comprida, 1.I.2002 (S. P. Rosa), 1 ex. (MZSP); sem localidade, sem data, sem coletor, 1 ex. (MNHN); idem, I.1961 (H. Schubart), 1 ex. (MNHN). Santa Catarina: Corupá, sem data (A. Maller), 3 exs (MNRJ); idem (Hansa Humboldt), 1933 (Ant. Maller), 7 exs (MNHN); idem, sem data, sem coletor, 1 ex. (MNRJ); idem, sem data, sem coletor, 1 ex. (MNRJ); sem localidade, sem data, sem coletor, 1 ex. (DEIC); idem, 4 exs. (MNHN); (Sta.Cathe.) sem localidade, 1890, sem coletor, 1 ex. (MNHN). Rio Grande do Sul: São Leopoldo, sem data (W. Stahl), 1 ex. (NHRS); sem localidade, sem data, sem coletor, 1 ex. (MNHN). PARAGUAI. Asunción, sem data (Anisits), 1 ex. (FMNH); Hohenau, Alto Paraná; 1954 (H. Jacob), 1 ex. (BMNH). ARGENTINA. Misiones (Territ. des Missiones), sem data, sem coletor, 1ex. (ISNB).

Comentários. Espécie semelhante a $O$. quadraticollis e a $O$. helvolus pela cor e pontuação do pronoto, e vesículas luminescentes pequenas e elípticas, mas difere de ambas pelos lados do pronoto arredondados e pelas características do pênis; de O. quadraticollis também pelas antenas mais curtas e ângulos posteriores do pronoto mais curtos e menos divergentes. As fêmeas de $O$. lucens podem ser confundidas com algumas fêmeas de $O$. pyrophanus e de $O$. costae por apresentarem os lados do pronoto e élitros arredondados, mas podem ser separadas destas duas últimas pela pontuação do pronoto mais fina, ângulos posteriores mais carenados, vesículas luminescentes menores e ápices dos élitros mucronados.

\section{Opselater melanurus (Candèze, 1863)} (Figs. 18, 22, 48-50, 61)

Pyrophorus melanurus Candèze, 1863: 23 (desc.). Lectótipo macho. Guiana Francesa. Cayenne, Coll. Janson ex de La Ferté, 1903-130 (BMNH) (não examinado). Schenkling, 1927: 352 (cat.); Blackwelder, 1944: 285 (cat.).
Opselater melanurus; Costa, 1975: 104, fig. 36 (rev.); 1980: 168, fig. 14 (chave, redesc., designação do lectótipo).

Macho. Tegumento de coloração geral (Fig. 61) castanhoescura. Antenas pretas ou castanhas, exceto três primeiros antenômeros amarelos ou castanho-claros. Pernas amareladas. Hipômeros amarelados ou castanho-claros. Epipleuras amareladas. Pronoto com faixa amarelada nas margens laterais aproximadamente duas vezes mais larga que o ângulo anterior. Élitros com metade anterior amarelada. Pilosidade curta, densa, amarela ou dourada.

Fronte quase plana, com pontuação, densa, forte e umbilicada. Antenas (Fig. 18) não ultrapassam os ângulos posteriores do pronoto; $4^{\circ}$ ao $10^{\circ}$ antenômeros curtos e fortemente serreados; $3^{\circ}$ antenômero com comprimento subigual $\left(1,2\right.$ vezes) ao do $2^{\circ}$.

Protórax com lados subparalelos. Pronoto (Fig. 22) regularmente convexo com pontuação forte, simples e densa na região discal; densa e umbilicada nas margens laterais. Vesículas luminescentes geralmente quase invisíveis, ocultas sob a pilosidade, pequenas e arredondadas, raramente ovais e oblíquas, convergentes posteriormente. Ângulos posteriores curtos, fortes, fracamente carenados e pouco divergentes. Prosterno com pontuação média e espaçada no processo prosternal; forte e densa nas margens laterais; forte e espaçada, da região anterior ao processo prosternal até a mentoneira. Hipômeros com pontuação média.

Órgão luminescente abdominal sub-retangular.

Élitros com strigae fortemente marcadas; interestrias achatadas, com pontuação fina e moderadamente densa; ápices afilados, deiscentes.

Edeago (Figs. 48-50). Pênis. Esclerito dorsal com lados sinuosos e ápice gradualmente afilado; abaulamentos laterais alongados e proeminentes; superfície látero-ventral da região anterior ao ápice lisa. Esclerito ventral com base um pouco mais estreita, lados divergentes até o quarto basal, convergentes até o ápice truncado e levemente emarginado.

Dimensões (em mm). Comprimento total: 16,8 -21,2. Comprimento do pronoto: 4,5-5,7. Largura do pronoto: 4,25,6. Largura umeral: 4,3-5,7. Comprimento dos élitros: 2,5 vezes o comprimento do pronoto.

Distribuição. Guiana Francesa, Brasil (Pará - segundo Costa, 1980; Mato Grosso), Peru (Ucayali, San Martin).

Material examinado: Sem país, sem localidade, sem data, sem coletor, 1 ex. (coll. Kraatz) (DEIC). GUIANA FRANCESA. Gourdonville, sem data, sem coletor, 2 exs. (col. Le Moult) (MNHN); St. Laurent du Maroni, sem data, sem coletor, 1 ex. (coll. Le Moult) (MNHN); Pariacabo, Rivière de Kourou, sem data, sem coletor, 1 ex. (coll. Le Moult) (MNHN); sem localidade, sem data, sem coletor, 2 exs. (MNHN). BRASIL. Mato Grosso: sem localidade, 1886 (P. Germain), 5 exs. (MNHN). PERU. (Amazonas) Tarapoto, $4^{\circ}$ trimestre, 1885 (M. de Mathan), 8 exs. (MNHN); Tarapoto, X.1886 (M. de Mathan) 9 exs. (MNHN); (Pucalipa) Ucayali: Pucallpa, Rio Ucayali $(200 \mathrm{~m})$, sem data, sem coletor, 1 ex. (Col. Dirings) (MZSP); Huallaga, próx. Yurimaguas, VI-X.1885 (M. de Mathan), 2 exs. (MNHN).

Comentários. A fêmea de O. melanurus não é conhecida. O 


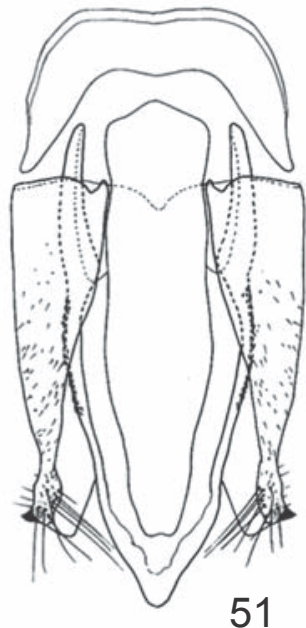

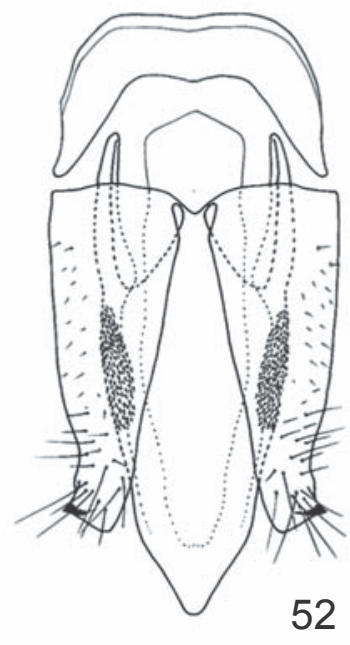

$1 \mathrm{~mm}$
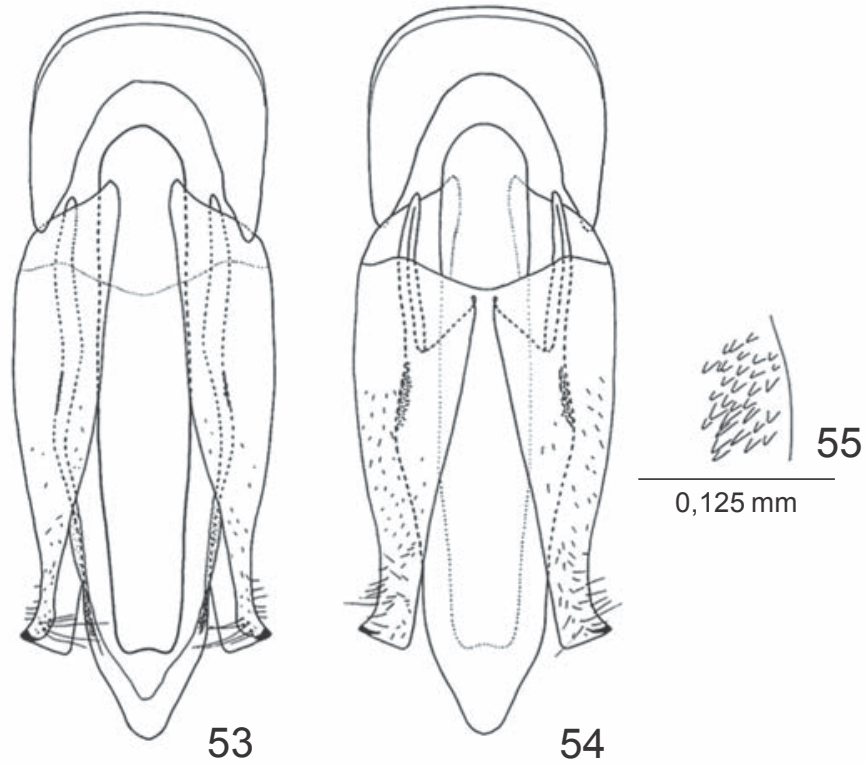

Figs. 51-55. Edeagos. Opselater succinus: 51, 52, ventral, dorsal. O. quadraticollis: 53, 54, ventral, dorsal; 55, escamas do esclerito dorsal do pênis. Figs. 51- 54 na mesma escala.

macho é caracterizado pelo pronoto e élitros bicoloridos. É similar a $O$. hebes, pelos caracteres já citados, e é semelhante a $O$. succinus pela convexidade do pronoto, cor e forma das antenas. Difere desta última pela coloração do pronoto e élitros, pontuação do pronoto menor e pelo esclerito dorsal do pênis com abaulamentos laterais mais proeminentes.

Opselater pyrophanus (Illiger, 1807)

(Figs.11, 13, 24, 28-38, 59)

Elater pyrophanus Illiger, 1807:149. Lectótipo macho. Brasil. Bahia. Gomes col., $\mathrm{n}^{\circ} 17140$ (ZMHB) (não examinado).

Pyrophorus pyrophanus; Germar, 1841: 38 (rev.). Candèze, 1863: 29, 1 fig. (rev.); Schenkling, 1927: 353 (cat.); Blackwelder, 1944: 286 (cat.).

Opselater pyrophanus; Costa, 1975: 105, figs. 35, 60-62, 161 (rev.); 1980: 169, figs. 11, 12 (chave, redesc., designação do lectótipo); Golbach, 1994: 43 (cat.).

Pyrophorus acuminatus Eschscholtz, 1829: 32 (desc.). Localidadetipo: Rio de Janeiro e Bahia. Candèze, 1863: 29 (syn.).; Schenkling, 1927: 353 (in syn., cat.); Blackwelder, 1944: 286 (in syn., cat.).

Pyrophorus acutipennis Castelnau, 1840: 236 (desc.). Localidade-tipo: Guiana- Francesa. Candèze, 1863: 30 (syn.); Schenkling, 1927: 353 (in syn., cat.); Blackwelder, 1944: 286 (in syn., cat.).

Pyrophorus angusticollis Eschscholtz, 1829: 32 (desc.). Localidadetipo: Rio de Janeiro. Germar, 1841: 74 (rev.); Candèze, 1863: 29 (syn.); Schenkling, 1927: 353 (in syn., cat.); Blackwelder, 1944: 286 (in syn., cat.).

Pyrophorus pyrrhoderus Germar, 1841: 37 (desc.). Localidade-tipo: Brasil. Bahia. Candèze, 1863: 29 (syn.); Schenkling, 1927: 354 (in syn., cat.); Blackwelder, 1944: 286 (in syn., cat.)

Pyrophorus quadricollis Eschscholtz, 1829: 32 (desc.). Localidadetipo: Rio de Janeiro. Germar, 1841: 75 (rev.); Candèze, 1863: 30 (syn.); Schenkling, 1927: 354 (in syn., cat.); Blackwelder, 1944:286 (in syn., cat.).

Pyrophorus illuminans Germar, 1841: 30 (parte) (desc.). Localidadetipo: Brasil. Candèze, 1863: 32 (rev.); Schenkling, 1927: 351 (cat.); Costa, 1980: 169 (syn.).
Macho. Tegumento de coloração geral (Fig. 59) castanhoclara a castanho-escura. Antenas geralmente amareladas ou castanhas mais claras que a cor geral do tegumento, raramente castanho-escuras. Pernas, hipômeros e epipleuras geralmente da mesma cor do tegumento. Pronoto uniformemente colorido, raramente com faixa longitudinal mediana mais escura. Élitros uniformemente coloridos. Pilosidade curta, densa, acizentada ou amarelo-clara.

Fronte côncava, com pontuação densa, média e umbilicada. Antenas (Fig. 13) ultrapassam os ângulos posteriores do pronoto a partir do $9^{\circ}$ ou $10^{\circ}$ antenômero; $4^{\circ}$ ao $10^{\circ}$ antenômeros alongados e normalmente serreados; $3^{\circ}$ antenômero mais longo ( 1,6 vezes) que o $2^{\circ}$.

Protórax com lados subparalelos. Pronoto (Fig. 24) pouco convexo com pontuação média, simples e moderadamente densa na região discal; densa e umbilicada nas margens laterais. Vesículas luminescentes visíveis, relativamente grandes, ovais e subparalelas. Ângulos posteriores delgados, fracamente carenados e pouco divergentes. Prosterno com pontuação fina e espaçada no processo prosternal; fina e densa nas margens laterais; forte, moderadamente densa a densa, da região anterior ao processo prosternal até a mentoneira. Hipômeros com pontuação fina.

Órgão luminescente abdominal (Fig. 11) subquadrangular ( 1,6 vezes mais largo que longo).

Élitros com strigae fortemente marcadas; interestrias achatadas, com pontuação fina e moderadamente densa; ápices afilados, pouco deiscentes.

Edeago (Figs. 33, 34). Peça basal com margem anterior quase reta ou profundamente emarginada. Pênis. Esclerito dorsal com lados gradualmente convergentes até o ápice abruptamente afilado; abaulamentos laterais geralmente ausentes, quando 
presentes são curtos, pouco proeminentes e com ou sem minúsculas escamas látero-dorsais; superfície látero-ventral da região anterior ao ápice lisa. Esclerito ventral com base um pouco mais estreita; lados levemente divergentes nos $2 / 3$ basais, convergentes no terço apical; ápice levemente emarginado.

Dimensões (em mm). Comprimento total. Macho: 15,6-21,5; fêmea: 19,4-24,4. Comprimento do pronoto. Macho: 3,9-5,2; fêmea: 4,9-5,7. Largura do pronoto. Macho: 3,7-5,0; fêmea: 5,0-6,3. Largura umeral. Macho: 3,8-5,6; fêmea: 4,9-6,4. Comprimentos dos élitros. Macho: $2,7-2,8$ vezes o comprimento do pronoto; fêmea: 2,6-3,0 vezes o comprimento do pronoto.

Distribuição. Brasil (Goiás, Mato Grosso, Pernambuco, Alagoas, Bahia, Espírito Santo, Rio de Janeiro, Minas Gerais, São Paulo, Paraná, Santa Catarina, Rio Grande do Sul ), Argentina (Pico).

Material examinado: Sem País, sem localidade, sem data, sem coletor, 1 ex. (402) (MZSP); idem, 9 exs.(coll. Chevrolat, coll. Fleutiaux) (MNHN); idem, 1 ex. (coll. Fleutiaux) (MNHN); idem,1952, sem coletor, 1 ex. (coll. R. Oberthur) (MNHN); idem, 1955, sem coletor, 1 ex. (Karl Brancsik coll.) (FMNH); idem, sem data, sem coletor, 2 exs. (MZSP); idem, 1952, sem coletor, 1 ex. (coll. R. Oberthur) (MNHN); idem , sem data, sem coletor, 3 ex. (MNHN); idem, 1 ex. (DEIC); idem, 2 ex. (MZHF); idem, 1 ex. (Col. H.) (MNRJ); idem, 1 ex. (coll. Candèze) (ISNB); idem, 1 ex. (coll. Janson, BMNH); idem, 1 ex. (coll. Kraatz) (DEIC); idem 1 ex. (det. E. Candèze) (ISNB); idem, 1 ex. (ex. Saunders. coll. Janson) (BMNH); idem, 1 ex. (Germ) (MNHN); idem, 1 ex. (Walkenaer) (MNHN); idem, 1 ex. (W. Schaws, coll. Hy. Edwards) (AMNH). BRASIL. Sem localidade, sem data, sem coletor, 1 ex. (NHRS); idem, 3 exs. (MNHN); idem, 7 exs. (DEIC); idem, 1 ex. (coll. Chevrolat) (MNHN); idem, 14 exs. (det. Candèze) (ISNB); idem, 1 ex. (Janson Coll, 1903-30) (BMNH); idem, 1952, sem coletor, 1 ex. (Col. R. Oberthur) (MNHN); idem, sem data, sem coletor, 1 ex. (coll. Chevrolat, coll. Fleutiaux) (MNHN); idem, 1 ex. (coll. E. Candèze) (ISNB); idem, 1 ex. (coll. F. C. Bowditeh) (MCZC); idem, 1 ex.(Guillemin Houlet, 290-39) (MNHN); idem, sem data (St. Hilaire), 1 ex. (MNHN); idem, sem data, sem coletor, 13 exs. (MZHF); idem, 1 ex. (NHRS); idem, 1 ex. (MNHN). Goiás: Jataí (Jatahy), sem data, sem coletor, 2 exs. (ZMHB). Mato Grosso: sem localidade, sem data, sem coletor, 1 ex. (De Castelnau; 13-47, MNHN); idem, 1886 (P. Germain), 1 ex. (MNHN). Pernambuco: Jaboatão, 1937 (L. Castro), 1 ex. (MZSP); Tapera, 1936 (A. Lins), 1 ex. (MZSP). Alagoas: Maceió, 1911, sem coletor, 2 exs. (Brandas Coll) (MNHN); Maceió, 2-6.II.1976 (Lane), 1 ex. (MZSP); S. Miguel, X.51 (E. Dante), 1 ex. (MZSP). Bahia: Cachimbo, 1890 (C. Pujol), 3 ex. (MNHN); Jequié, II.1964 (N. Papavero), 1 ex. (MZSP); Ilhéus, Faz. São Caetano, sem data, sem coletor, 1 ex. ( col. Dirings) (MZSP); sem localidade, sem data, sem coletor, 1 ex. (coll. Candèze) (ISNB); idem, 1 ex. (MZSP); idem, 2 exs. (DEIC); idem, 7 exs. (MNHN); idem, 1 ex. (coll. Schwarz) (DEIC); sem localidade, 1913 (P. Serre), 1 ex. (MNHN). Espírito Santo: Córrego Itá, XI.1954 (W. Zikan), 1 ex. (MNRJ); Santa Leopoldina, sem data, sem coletor, 1 ex. (MNHN); sem localidade, sem data, sem coletor, 1 ex. (BMNH). Rio de Janeiro: Retiro Pedro do Rio, III.1954, 1 ex. (MNRJ); Mendes (A 92km do Rio de Janeiro), sem data, sem coletor, 1 ex. (coll. Le Moult) (ISNB); Corcovado, III.1967 (Alvarenga e Seabra), 2 exs. (MZSP); Corcovado 18.II.1960 (D. Zajciw), 1 ex. (MZSP); Floresta da Tijuca, I.1954, sem coletor, 1 ex. (MNRJ); Corcovado, I.1955 (D. Zajciw), 1 ex. (MZSP); Corcovado II.1956 (D. Zajciw), 2 exs. (MNRJ); Serra dos Órgãos (Montagnes des Orgues), 1902 (E. R. Wagner), 8 exs. (MNHN); Serra dos Órgãos (Paraná: Montagnes des Orgues), 1901 (E. R. Wagner), 1 ex. (MNHN); Petrópolis, sem data, sem coletor, 1 ex. (MNHN); Petrópolis, sem data, sem coletor, 3 exs. (19092, 19086, 19086) (MZHF); Tijuca, 3-934 (MNRJ), 1 ex. (MNRJ); Tijuca, 03-937 (Seabra), 1 ex. (MNRJ); Rep. Rio Grande, 20.I.1967,
15.II.1967, 2.III.1967 (F.M. Oliveira), 3 exs. (MZSP); sem localidade, 1844 (De Castelnau), 3 exs. (MNHN); idem, sem data, sem coletor, 7 exs. (MNHN); idem, sem data (Dr. Korber), 1 ex. (MNHN); idem, sem data, sem coletor, 1 ex. (9836, MNHN); idem, 1909, sem coletor, 1 ex. (coll. Fry, BMNH); idem, sem data, sem coletor, 3 exs. (Fry coll, 1905.100, BMNH); idem, 2 exs. (19090, 19093, MZHF); idem, 2 exs. (NHRS); idem, 1ex. (MNHN); idem, 1 ex. (coll. E Candèze) (ISNB); idem, 1 ex. (col. Kraatz) (DEIC). Minas Gerais: Caraça, sem data, sem coletor, 1 ex. (MNHN); Caraça, $2^{\circ}$ semestre de 1884 (P. Germain), 1 ex. (MNHN); Mar de Espanha, sem data, sem coletor, 1 ex. (MNHN); Viçosa, sem data (Snipes), 2 exs. (IBSP); Serra do Caraça, 27.XI.1972 (Exp. MZUSP), 15 exs. (MZSP). São Paulo: Ipiranga, sem data, sem coletor, 1 ex. (MZSP); idem, II.1943 (Navajas), 1 ex. (MZSP); idem, 1909, sem coletor; 1 ex. (MZSP); idem, 1912, sem coletor, 1 ex. (MZSP); idem, I.34, sem coletor, 3 exs. (MZSP); idem, sem data, sem coletor, 1 ex. (MNHN); idem, sem data, sem coletor, 6 exs. (MZSP); idem, sem data, sem coletor, 1 ex. (7208, MZSP); idem, 1909, sem coletor, 1 ex. (MZSP); idem, sem data, sem coletor, 1 ex. (coll. M. A., 12.932) (IBSP); São Bernardo, III.27 (R. Spitz), 1 ex. (MZSP); Barueri, 14.II.1969 (K. Lenko), 1 ex. (MZSP); Salesópolis (Boracéia), V.49 (D. Braz), 1 ex. (IBSP); Capital 1-933, sem coletor, 1 ex. (coll. B.L.R.) (MZSP); idem, sem data, sem coletor, 2 exs. (2.934) (IBSP); idem, 1 ex. (coll. J. Guerin) (IBSP); idem, 1 ex. (12.940) (IBSP); idem, 1 ex. (42) (MZSP), idem, 1 ex. (44) (MZSP); idem, 1 ex. (MZSP); Diadema, 12.II.1961 (Reichardt), 1 ex. (MZSP); Ilha Comprida, 05.XII.2001 (S. P. Rosa), 30 exs. (MZSP); São Sebastião, Ilha de Alcatrazes, 27.II.94 (R. B. Francini), 2 exs. (MZSP); Ilha dos Búzios, 16.X-4.XI.1963 (Exp. Dep. Zool), 1 ex. (MZSP); Ilha Queimada Grande, 25.XI.1954 (Prof. Robert Mertens), 1 ex. (SMFD); Itatiaia, 1 ex., sem data (Pohl), 1 ex. (MZSP); Jabaquara, 1.II.1964 (J. Sassi), 1 ex. (MZSP); idem, II.1946 (J. Guer.), 1 ex. (IBSP); idem, sem data (Dirings), 3 exs. (MZSP); Parque Bristol, 23.XI.1967 (B.N. Dias), 1 ex. (MZSP); Rio Piracicaba, II.1885 (P. Germain), 10 exs. (MNHN); Santo André, Vila Bastos, II.1962 (L. Stowbunenko), 1 ex. (MZSP); São Bernardo, sem data; sem coletor, 1 ex. (2.934) (IBSP); idem, 24.I.28 (R. Spitz), 1 ex. (MZSP); idem, III.1927 (R. Spitz), 1 ex. (MZSP); São J. Campos, sem data, sem coletor, 1 ex. (coll. D. B, 2.935) (IBSP); Itanhaem, Suarão, 3.III.1962 (J. D. Cardoso), 1 ex. (MZSP); V. Caraguatá, P. Bristol, 22.I.1966 (B. N. Dias), 13 exs. (MZSP); idem, 13.XII.1965 (B. N. Dias), 1 ex. (MZSP); idem, 30.I.1966 (B.N. Dias), 3 exs. (MZSP); sem localidade, sem data, sem coletor, 1 ex. (H. C. Fall coll) (MCZC); idem, 1 ex. (IBSP); sem localidade, 03.II.1968 (K. Lenko), 1 ex. (MZSP); idem, XI.1934 (R. Spitz), 1 ex. (MZSP). Santa Catarina: Corupá, sem data (A. Maller), 2 exs. (II, III., CS); Corupá (Hansa Humboldt), 1933 (Aut. Maller), 5 exs. (MNHN); sem localidade, sem data, sem coletor, 1 ex. (MNHN); idem, 1 ex. (coll. Fleutiaux) (MNHN). Rio Grande do Sul: Osório, 23.I.58 (Pe. Buck), 1 ex. (4440) (MAPA). ARGENTINA. Pico, sem data (H.L. Parker), 1 ex. (USNM).

Comentários. Esta é uma das espécies mais comuns de vaga-lumes. Os machos são identificados por sua coloração castanha uniforme, pelo pronoto de lados subparalelos, pouco convexo; vesículas luminescentes ovais, relativamente grandes e antenas longas.

\section{Opselater quadraticollis (Blanchard, 1843) (Figs.15, 26, 53-56)}

Pyrophorus quadraticollis Blanchard, 1843: 140 (desc.). Lectótipo fêmea. Bolívia, Santa Cruz de la Sierra, D’Orbigny col., 1834, $\mathrm{n}^{\circ}$ 6378-34 (MNHN) (não examinado). Candèze, 1863: 30 (syn. com P. pyrophanus Illiger, 1807); Schenkling, 1927: 354 (in syn., cat.); Blackwelder, 1944: 286 (in syn., cat.).

Opselater quadraticollis; Costa, 1975: 105, fig. 30 (reval.); 1980: 171 (chave, redesc., designação do lectótipo).

Macho. Tegumento de coloração geral (Fig. 56) castanho- 

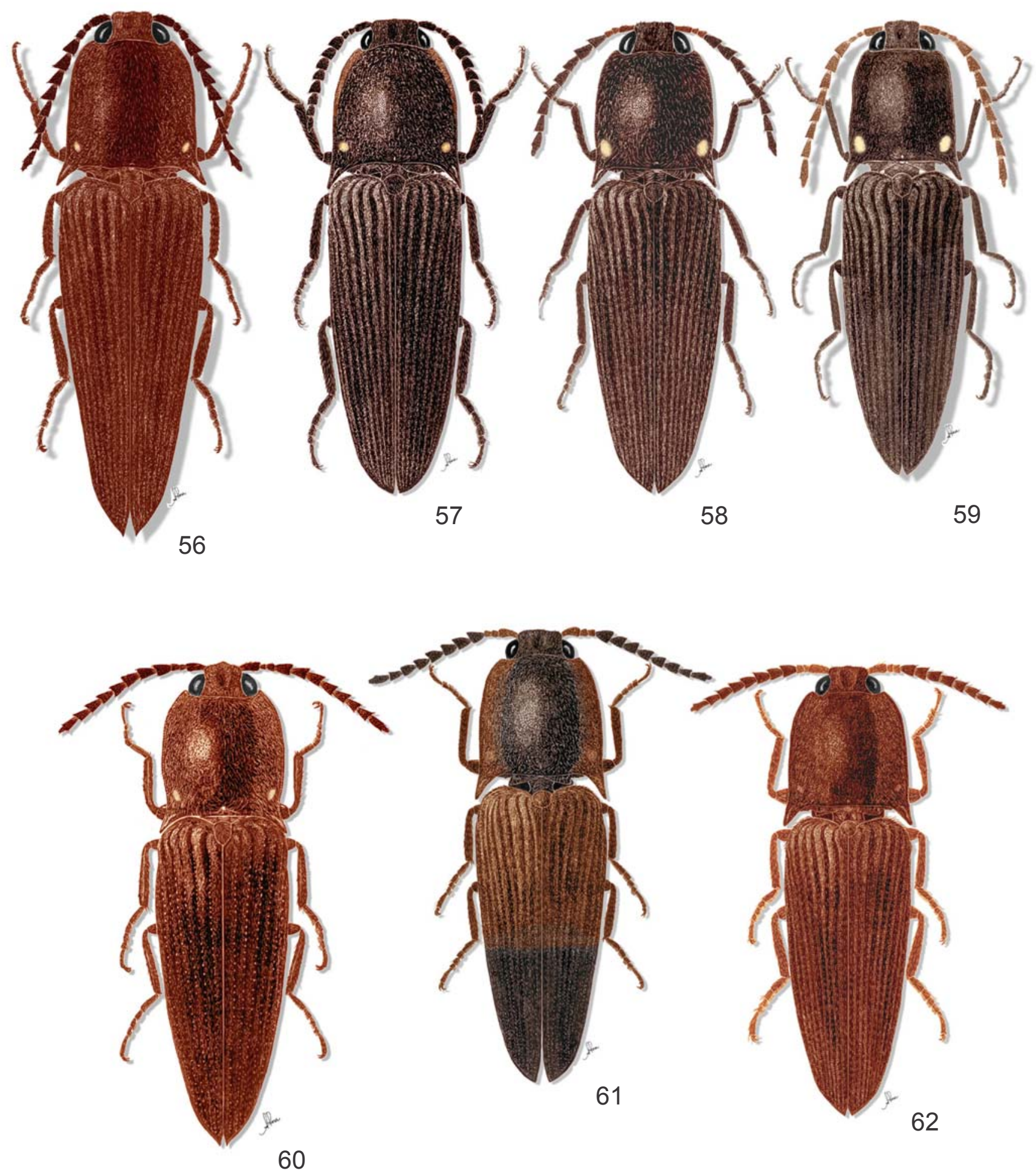

Figs 56-62. Aspecto geral (macho): 56, Opselater quadraticollis $(24,0 \mathrm{~mm}) ; \mathbf{5 7}$, O. hebes $(21,6 \mathrm{~mm}) ; \mathbf{5 8}, O$. costae sp. nov. (20,8 mm); 59, O. pyrophanus $(20,0 \mathrm{~mm}) ; \mathbf{6 0}$, O. lucens $(25,8 \mathrm{~mm}) ; \mathbf{6 1}$, O. melanurus $(20,5 \mathrm{~mm}) ; \mathbf{6 2}$, O. succinus $(20,4 \mathrm{~mm})$. 
avermelhada, clara ou escura. Antenas castanhas ou castanhoescuras. Pernas geralmente da mesma cor do tegumento. Hipômeros e epipleuras amarelados ou castanho-claros. Pronoto com faixa longitudinal mediana preta ou castanha mais escura que as margens laterais, de largura aproximadamente igual a um terço da largura total do pronoto. Élitros uniformemente coloridos. Pilosidade curta, densa e acizentada.

Fronte côncava, com pontuação densa, fina e umbilicada. Antenas (Fig. 15) ultrapassam os ângulos posteriores do pronoto a partir do $11^{\circ}$ antenômero; $4^{\circ}$ ao $10^{\circ}$ antenômeros alongados e normalmente serreados; $3^{\circ}$ antenômero mais longo (1,5 vezes) que o $2^{\circ}$.

Protórax com lados subparalelos. Pronoto (Fig. 26) pouco convexo com pontuação fina, simples e moderadamente densa na região discal, densa e umbilicada nas margens laterais. Vesículas luminescentes visíveis, pequenas, ovais e oblíquas, convergentes posteriormente. Ângulos posteriores delgados, carenados e divergentes. Prosterno com pontuação fina e espaçada no processo prosternal; fina e densa nas margens laterais; média, moderadamente densa da região anterior ao processo prosternal até a mentoneira. Hipômeros com pontuação fina.

Órgão luminescente abdominal subquadrangular.

Élitros com strigae fracamente marcadas; interestrias achatadas, com pontuação muito fina e moderadamente densa; ápices geralmente mucronados, deiscentes.

Edeago (Figs.53-55). Pênis. Esclerito dorsal com lados sinuosos, ápice gradualmente afilado; abaulamentos laterais curtos e pouco proeminentes; superfície látero-ventral da região anterior ao ápice com minúsculas escamas. Esclerito ventral de lados paralelos, ápice de mesma largura, emarginado.

Dimensões (em mm). Comprimento total: 19,7-20,5. Comprimento do pronoto: 4,8-5,0. Largura do pronoto: 4,55,0. Largura umeral: 4,7-5,0. Comprimento dos élitros: 2,8 vezes o comprimento do pronoto.

Distribuição. Bolívia (Santa Cruz de la Sierra) (segundo CosTA, 1980), Brasil (Goiás, Mato Grosso do Sul, São Paulo).

Material examinado: BRASIL. Goiás: Jataí, sem data, sem coletor, 2 exs. (ZMHB); Mato Grosso do Sul: Maracaju, 3-937 (Shannon Lane), 1 ex. (MZSP- comparado com o tipo). São Paulo: Botucatu, IV.1974 (Mantovani), 1 ex. (MZSP); sem localidade, sem data, sem coletor, 1 ex. (MNHN).

Comentários. A única fêmea conhecida para esta espécie é o exemplar descrito por BLANCHARD (1843) que foi examinado por Costa (1980) e descrito por esta autora como sendo maior, mais arredondada e com antenas mais curtas. Espécie muito semelhante a $O$. lucens pelas características já discutidas. $\mathrm{O}$ macho de $O$. quadraticollis caracteriza-se pelo pronoto com lados subparalelos e margens laterais amareladas, antenas longas e ápices dos élitros bastante afilados ou mucronados.

Opselater succinus Costa, 1980

(Figs.12, 17, 20, 51, 52, 62)

Opselater succinus Costa, 1980: 171, figs. 15, 20 (chave, desc.).
Holótipo macho. Brasil. Bahia. Coll. Janson (BMNH) (não examinado)

Macho. Tegumento de coloração geral (Fig. 62) castanhoavermellhada, clara ou escura. Antenas geralmente da mesma cor do tegumento com três primeiros antenômeros mais claros. Pernas, hipômeros e epipleuras amarelados ou castanhos mais claros que a cor geral do tegumento. Pronoto com faixa longitudinal mediana preta ou castanha mais escura que as margens laterais, de largura aproximadamente igual a um terço da largura total do pronoto. Élitros uniformemente coloridos. Pilosidade curta, densa, amarela.

Fronte quase plana, com pontuação densa, forte e umbilicada. Antenas (Fig. 17) não ultrapassam os ângulos posteriores do pronoto; $4^{\circ}$ ao $10^{\circ}$ antenômeros curtos e fortemente serreados, $3^{\circ}$ antenômero com comprimento igual (1,0 vez) ao do $2^{\circ}$.

Protórax com lados arredondados ou levemente arredondados. Pronoto (Fig. 20) regularmente convexo com pontuação forte, simples e densa na região discal; densa e umbilicada nas margens laterais. Vesículas luminescentes quase invisíveis, ocultas sob a pilosidade, pequenas, ovais e oblíquas, convergentes posteriormente. Ângulos posteriores fortes, carenados e divergentes ou pouco divergentes. Prosterno com pontuação fina e espaçada no processo prosternal; média e densa nas margens laterais; forte e espaçada, da região anterior ao processo prosternal até a mentoneira. Hipômeros com pontuação média.

Órgão luminescente abdominal (Fig. 12) sub-retangular (2,2 vezes mais largo que longo).

Élitros com strigae fortemente marcadas, interestrias achatadas, com pontuação fina e moderadamente densa; ápices afilados; pouco deiscentes.

Edeago (Figs. 51, 52). Pênis. Escleritos com lados levemente sinuosos, ápice abruptamente afilado; abaulamentos laterais alongados e pouco proeminentes, com escamas da superfície látero-dorsal um pouco mais alongadas; superfície láteroventral da região anterior ao ápice lisa. Esclerito ventral de lados subparalelos nos $2 / 3$ basais, gradualmente convergentes no terço apical; ápice levemente emarginado.

Dimensões (em mm). Comprimento total. Macho: 18,5-22,2; fêmea: 22,5. Comprimento do pronoto. Macho: 5,0-5,6; fêmea: 5,9. Largura do pronoto. Macho: 5,0-5,5; fêmea: 6,0. Largura umeral. Macho: 5,1-5,7; fêmea: 6,0. Comprimento dos élitros. Macho: 2,4-2,7 vezes o comprimento do pronoto; fêmea: 2,5 vezes o comprimento do pronoto.

Distribuição. Brasil (Bahia, Espírito Santo).

Material examinado. Sem país, sem localidade, sem data, sem coletor, 1 macho, parátipo, (coll. Janson, BMNH). BRASIL. Bahia: Una, Rio Aliança, 19.XII.1946, (P. Silva), 1 macho, parátipo (IBSP); sem localidade, sem data, sem coletor, 1 macho, parátipo (col. Fry, 1905.100, BMNH). Espírito Santo: sem localidade, sem data, sem coletor, 1 ex. (MNHN); Linhares, XII.1972, 2 exs. P. C. Elias (MZSP).

Comentários. Dos cinco parátipos examinados, duas não 
possuíam os caracteres descritos e ilustrados por CosTA (1980) para esta espécie e eram na realidade exemplares de $O$. lucens. $O$. succinus é semelhante a $O$. melanurus pelas características já discutidas e compartilha com $O$. hebes a forma das antenas e o tipo de pontuação do pronoto, mas difere desta última por apresentar pontuação do pronoto um pouco mais fina, corpo castanho avermelhado, faixa longitudinal do pronoto escura e esclerito dorsal do pênis com abaulamentos menos proeminentes.

Agradecimentos. À Dra. Cleide Costa, pela orientação e apoio; ao Dr. Sergio Ide, pelas sugestões e correção do texto. Ao Museu de Zoologia de São Paulo pelo acesso às instalações e recursos, pelo uso das coleções e biblioteca do Museu. Ao Michael, pela ajuda nas coletas, pelo carinho e amizade. Ao Instituto de Biociências da USP, por recursos e verbas, concedidos através do PROAP. À CAPES pela concessão da bolsa de estudo durante o período de agosto/2000-setembro/2002. O presente trabalho foi realizado com o apoio do CNPq.

\section{REFERÊNCIAS}

Becker, E. C. 1956. Revision of the Nearctic species of Agriotes (Coleoptera: Elateridae). The Canadian Entomologist 88 (supl. 1): $1-101$.

Billberg, G. J. 1820. Enumeratio insectorum in museo Billerg. Stockholm, $138 \mathrm{p}$.

Blackwelder, R. E. 1944. Checklist of the Coleopterous Insects of Mexico, Central America. the West Indies and South America. Bulletin of United States National Museum 185 (2): 280303.

Blanchard, E. 1843. In: Brullé, A. Voyage dans l'Amerique Meridionale. Insectes Coléoptères. Paris, p.140.

Bokermann, W. C. A. 1966. Lista anotada das localidades tipos de anfíbios brasileiros. São Paulo, Universidade de São Paulo, 183 p.

Calder, A. A. 1981. The Madagascan click beetle genus Crepicardus (Elateridae) and its relationship to the Pyrophorinae. Systematic Entomology 6: 355-72.

Calder, A. A. 1996. Click Beetles: Genera of Australian Elateridae (Coleoptera). Monographs on Invertebrate Taxonomy. Collingwood, CSIRO Publishing, v. 2, $\mathrm{x}+401 \mathrm{p}$

Calder, A. A.; J. F. Lawrence \& J. W. H. Trueman. 1993. Austrelater, gen. nov. (Coleoptera: Elateridae), with description of the larva and coments on elaterid relationships. Invertebrate Taxonomy 7: $1349-1394$.
Candèze, E. 1863. Monographie des Élatérides. Tome quatriême. Mémoires de la Société Royale des Sciences de Liége 17: 1534.

Candèze, E. 1891. Catalogue Méthodique des élatérides connus em 1890. Liège, H. Vaillant-Carmanne, xii $+246 \mathrm{p}$.

CASARI-Chen, S. A. 1993. Systematics and evolution of Hemirhipini from Old World and Australia. I. Genera removed from tribe (Coleoptera, Elateridae, Pyrophorinae). Revista Brasileira de Entomologia 37(2): 223-262

CAsari-Chen, S. A. \& C. Costa 1986. Larvas de Coleoptera da Região Neotropical XV. Revisão de Pyrophorini (Elateridae, Pyrophorinae). Revista Brasileira de Entomologia 30(2): 323357.

Castelnau, F. L. N. C. Laporte, Comte De. 1840. Histoire Naturelle des Insectes Coléoptères. Paris, P. Duménil, v. 1, 324 p..

Costa, C. 1975. Systematics and evolution of the tribes Pyrophorini and Heligmini with description of Campyloxeninae, new subfamily (Coleoptera, Elateridae). Arquivos de Zoologia 26(2): 49-191.

Costa, C. 1978. Sistemática e bionomia de Pyrearinus Costa, 1975 (Coleoptera, Elateridae). Arquivos de Zoologia 20(4): 185-236.

Costa, C. 1980. Novas espécies dos gêneros Ignelater e Opselater (Coleoptera, Elateridae, Pyrophorinae). Papéis Avulsos de Zoologia 33(7): 157-176.

Eschscholtz, J. F. 1829. Eintheilung der Elateriden in Gattungen. In Thon. Entomologische Archiv. Jena, v.2, p. 31-35.

Germar, E. F. 1841. Beiträge zu einer Monographie der Gattung Pyrophorus. Zeitschrift für die Entomologie 1(2): 193-236.

Golbach, R. 1994. Elateridae (Coleoptera) de la Argentina. Historia, catálogo actualizado hasta 1991 inclusive y clave de subfamilias y de géneros de Centro y Sudamérica. Opera Lilloana 41: 1-48.

Hanson, E. P. (ed.). 1945. Index to map of Hispanic America 1: 1000 000. Washinton, American Geographical Society/ United States Government, $923 \mathrm{p}$.

Illiger, J. C. W. 1807. Monographie der Elateren mit leuchtenden flecken auf dem halsschilde. Magazin der Gesellschaft Naturforschender Freude 1: 141-151.

Kukalová-Peck, J. \& J. F. Lawrence. 1993. Evolution of the hind wing in Coleoptera. The Canadian Entomologist 125(2): 181-258.

Lawrence J. F. \& E. B. Britton.1994. Australian Beetles. Victoria, Melbourne University Press, $\mathrm{x}+192 \mathrm{p}$.

Schenkling, S. 1927. Elateridae II. Coleopterorum Catalogus. Berlin, W. Junk, pt. 88 , n. 11 , p. 265-639.

Stephens, L. \& M. A. Traylor JR. 1983. Ornithological Gazetteer of Peru. Harvard, Harvard College, 271 p.

Sturm, J. 1843. Catalog der Kaefer-Sammlung von Jacob Sturm Nürnberg, $386 \mathrm{p}$

Vanzolini, P. E. \& N. Papavero. 1968. Índice dos topônimos contidos na carta do Brasil 1: 1000000 do IBGE. São Paulo, Fundação de Amparo à Pesquisa do Estado de São Paulo, 201 p.

Williams, J. L. 1945. The Anatomy of the internal genitalia of some Coleoptera. Proceedings of the Entomological Society of Washington 47(4): 73-87. 